\title{
Win-win and no-win situations in supply chain finance: The case of accounts receivable programs
}

\begin{abstract}
The paper aims to investigate whether supply chain finance (SCF) solutions have the potential to create tripartite value in the international trade arena. Distinguishing three actors, this value proposition is examined by modeling an accounts receivable platform (ARP) program. The setting is adapted to a supply chain with an OECD supplier and non-OECD buyers. The paper identifies trends in parameter values that bring about various situations, in which all parties benefit sufficiently in any total win situation. However, they are most likely limited to trade flows of higher valued goods that are frequently traded. For the supplier acting as the focal company and the financial institutions, these programs are only feasible if a large number of participants (buying customers) can be convinced to take part in the financing alternative. The resulting benefits are unlikely to be shared on even terms between the actors. If successfully implemented, the focal company will benefit most from the supply chain finance solution.
\end{abstract}

Keywords: Finance, Supply chain management, Working capital management, Financial intermediation, Advanced factoring

\section{Introduction}

\subsection{Starting situation}

Supply chain finance (SCF) has long been acknowledged as a concept that mainly benefits the participants inside a certain (dyadic) business relationship and that leads to a win-win situation (WWS) both for the supplier and the buyer (Lambert and Cooper, 2000). This paper aims to build on this notion. But at the same time, it tries to extend this view by addressing a prevalent belief among both practitioners and academics that suggests that SCF has the potential to create value for an additional actor in the financial supply chain (FSC): the financial institution (FI).

As banks go through heavy storms post financial crises, the demand for SCF solutions is still rising. With trade and sourcing options becoming more global and therefore harder to monitor, the role of FIs and specialized financial service providers (FSPs) in providing adequate financing solutions is growing. As supply chain (SC) networks have become more geographically dispersed and as competition has occurred increasingly on an interorganizational network level, the underlying differences in business conditions between developed and emerging countries has remained big (Camerinelli, 2009b). In particular, SCF addresses this gap by providing instruments for firms that foster the import and export mechanisms and allow firms to optimize their working capital (WC) at the same time (Hofmann, 2005). 


\subsection{Integrating financial flows in supply chain management}

Supply chain management (SCM) deals with integrating "information, material and financial flows in a way that matches supply with demand for the firm's products and services" (Kouvelis and Zhao, 2012, p. 250). More specifically, the management of financial flows in the SC involves an efficient allocation of financial resources and a reduction in financial needs along the chain. Figure 1 illustrates such a constellation and introduces the relevant supply chain actors (SCAs), colloquially called “arena of supply chain finance.”

\section{Figure 1: The arena of supply chain finance}

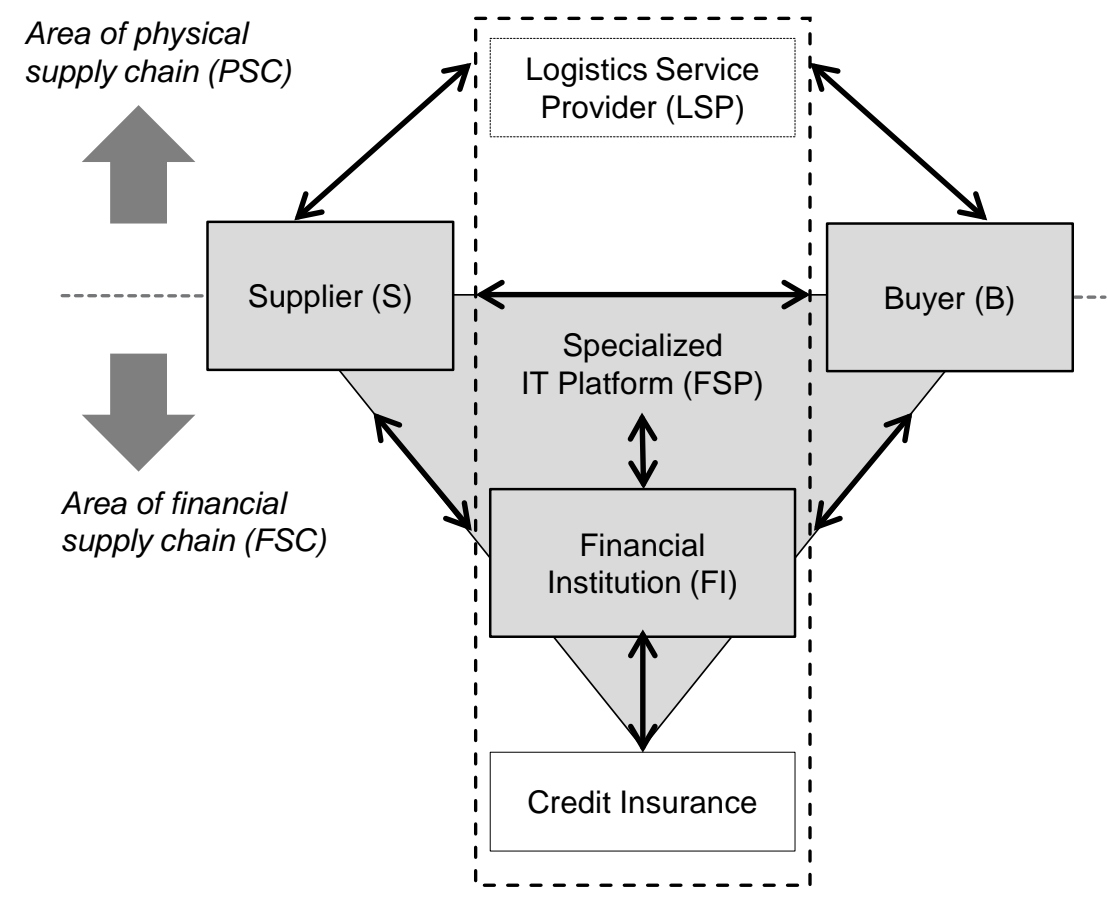

Apart from the truly finance-relevant actors, there are obviously more supply chain players involved within a certain value chain. To limit the scope of this work and in order to answer the inherent research question, this paper will mainly focus on the (gray) triangle of SCF highlighted in Figure 1. This essentially means that the physical flow of goods as well as the information flow will not be considered at a later stage as far as they are not clearly connected to the financial flow (e.g., invoices). Looking only at one supplier and buyer, Hofmann (2005, p. 4) notes that this is the simplest and most "minimal supply chain imaginable."

With regards to a FI, one must keep in mind that it is not a genuine member of a supply chain. However, a FI can be considered as a member of the FSC and might take various roles in this respect (Fairchild, 2005). On the one hand, FIs are enablers in the sense of consulting on innovative financing alternatives, and on the other hand, they can be direct intermediaries (e.g., act as a lender) to a supplier or buyer, as can be seen later on. Furthermore, it has to be noted 
that specialized "financial service platforms" (FSPs) have been successfully established in the SCF market, for example, companies such as Orbian (www.orbian.com), PrimeRevenue (www.primerevenue.com), GSCF (www.gscf.com), Bolero (www.bolero.net), or CRX Markets (www.crxmarkets.com). Such service providers mostly act as IT-based intermediaries and transaction platforms. For the purpose of clarity, we will not consider these intermediaries in our research separately (but rather as an integrated service of FIs).

Central to SCF is the question of how companies finance their physical (material) flows and how this might add value to the overall economic performance of a corporation (or even a whole supply chain network). Kouvelis and Zhao (2012) note that past research on SCM has largely ignored this view. As the need for integrated SCF solutions is growing, platform solutions have also gained prominence in the corporate world. Compared to more traditional approaches, such as letter of credits that are used to intermediate trades between corporations of different sizes, integrated solutions are usually used for mediating trade flows between a focal company (FC)—a large multinational firm—and its suppliers (accounts payable side) or buyers (accounts receivable side) both in the import as well in the export context. Indeed, a player that facilitates such transactions is the FI.

\subsection{Research objective and outline}

The goal of this paper is to develop an understanding about constellations that can lead to a benefit for all involved parties (supplier, buyer, and FI) in the new context of network finance and, more specifically, where SCF platforms are used. Such triple-win situations (TWS) may or may not be temporary. The likelihood that a specific party has a considerable advantage that outweighs the benefit of other supply chain actors (SCAs) might also exist. This novel view of TWS is largely unexplored by academic research and therefore calls for an in-depth analysis.

The design of the paper can be described as follows: Following the introduction, Section 2 presents a structured literature review aiming to build a sound theoretical foundation of a WWS and how it connects to SCF. The goal hereby is to learn more about the prevalent characteristics of these optimal situations that are commonly referred to. Section 3 first conceptualizes the network finance approach. The main emphasis then is shifted to a model (Section 4) to derive the net benefits of an accounts receivable platform (ARP) program. For each of the involved parties, a separate analysis is provided (Section 5), and the win respectively no-win notion is tackled and discussed in depth. Furthermore, a scenario analysis is done to test the validity of a TWS. The findings gained from the model then build the foundation for the discussion part in Section 6 . A critical reflection on the triple-win notion will be necessary to draw a conclusion 
for this new SCF value proposition. The paper closes by outlining the limitations as well as the implications for practitioners and theory (Section 7).

\section{Literature review}

\subsection{Win-win in supply chain management}

From the early literature on SCM, it can be inferred that the term win-win has been closely associated with the idea of an integrated supply chain (Towill, 1997). Integration hereby mainly referred to closer collaboration of the involved parties in the physical product flow. Vlachos (2004, p. 172) noted that creating a WWS would require firms to enter into some form of "cooperative scheme.” The collaboration should in turn lead to a mutual benefit for the involved parties over an extended time period. This view was already mentioned by Cooper and Ellram (1993), who stated that the time horizon in a SC partnership is essential, since considerable investments are needed for the implementation of a WWS. Furthermore, the terms win-winrelationship and long-term strategic alliance are often used simultaneously, which again emphasizes the time issue.

In simple terms, Maloni and Benton (1997, p. 420) describe a WWS as "a partnership that creates a synergistic supply chain in which the entire chain is more effective than the sum of its individual parts.” They note that these partnerships are often related to an increased financial performance as well as to a reduction in uncertainty (risk) for the involved partners. Giannoccaro and Pontrandolfo (2004, p. 132) give a similar definition and state that a win-win condition occurs "if under the contract every SC actor obtains a profit higher than he/she would do without a contract. Otherwise the SC actor would not be prompted to adopt the contract.” Whereas the first definition does not narrow down the term exactly, the second one is more precise and clearly suggests that a financial benefit (profit) should be a necessary outcome of a WWS. However, from both definitions, one can infer that each SCA should derive some utility from a given partnership, collaboration, or SC contract.

According to Gunasekaran et al. (2001), an enhanced supplier-buyer relationship (a WWS) can be measured with both financial and nonfinancial performance metrics. While it is not the goal to introduce specific performance measures (e.g., economic value added or others), we will highlight henceforward the mechanics of WWS and investigate whether a WWS implies that all SCAs derive a similar benefit from a certain initiative.

Vlachos (2004) notes that SCAs aiming to derive mutual benefits (WWS) also likely pursue joint investments in projects, such as those related to technology. A common investment in this field could pay off later if the SCAs' future business relationship is mutually dependent on such 
a system (e.g., IT). From an investment perspective, Corbett and Decroix (2001) note that if SCAs invest jointly, the joint costs that arise should also be shared. However, they leave the question open as to how and to what extent these costs should be shared.

Another stream of literature suggests that individual firms may be willing to accept lower benefits if the overall SC performance can be enhanced (Lanier et al., 2010). This is in line with the findings of Chandra and Kumar (2000), who state that the success of a single company is strongly dependent on a successful SC in the long term.

\subsection{Win-win in supply chain finance}

The academic contribution to specific win-win partnerships in SCF is rare and often limited to conceptual discussions. In general, two different WWS might be distinguished in the context of this paper. First, suppliers and buyers engage in SCF solutions because they are driven by the constant goal to optimize WC. Secondly, the banks take steps to enhance the relationships with their corporate client base while their customers can access funds through innovative financing mechanisms.

Focusing on the first type of WWS, the efficiency of WCM is often measured by the cashto-cash cycle (C2C) (Farris II and Hutchinson, 2003), also known as the cash conversion cycle. The C2C indicates the time span (usually in days) between the point of time that a firm has to pay for its company resources (AP) and the date it can collect its receivables (AR). ${ }^{1}$ A SCF solution should therefore ideally have a positive impact on the $\mathrm{C} 2 \mathrm{C}$ metric for both the supplier and the buyer if the aim is to achieve a WWS (Hofmann and Kotzab, 2010). This notion, however, is in contrast to Randall and Farris II (2009), who stated that individual firms often have to accept an increase in their own C2C measure if they aim to support partners in their network. But their analysis rests on case studies targeting C2C optimizations for a SC without the support of an external party (a FSP or a FI). Empirical studies do not present a consistent picture. For example, the significance of an efficient WCM and its link to company profitability has been proven both for firms domiciled in OECD countries (e.g., Deloof, 2003, for a set of Belgian firms) and non-OECD countries (e.g., Raheman and Nasr, 2007, for a set of Pakistani firms). But on the contrary, Baños-Caballero et al. (2010) show that small- and medium-sized enterprises (SMEs) have a target C2C length to which they attempt to converge. More closely related to our aim is the work of Hofmann and Belin (2011), which will also serve as a basis for the

\footnotetext{
${ }^{1}$ Formally, Farris II and Hutchinson (2003) define the C2C in their paper as follows: $C 2 C=$ Inventoryc2C + ReceivablesC2C Payablesc2C. The first component with regards to the inventory turnover (days of inventory held) is irrelevant for the purpose of this paper.
} 
model used later on in the paper. Their model calculations reveal that for an accounts receivable program targeting OECD to non-OECD directed exports, the potential net benefits for the FCs (exporting suppliers) is roughly three times as high as for its buyers. In their cost-benefit analysis, they also show that the benefits from SCF solutions are not limited to increase the net working capital level, but administrative advantages (efficiency enhancements) could also arise. Seifert and Seifert (2010, p. 38) argued in a similar direction and stated that a true WWS in SCF “goes beyond a simple adaption of payment terms" but should also take into account specific platforms that allow electronic processing of additional relevant information that was previously exchanged physically (e.g., invoices). This highlights another cornerstone of a WWS in SCF between buyers and suppliers, namely, the risk component and therefore the question of how to make the financial flows more visible and transparent.

The second WWS deals more closely with the FI and the question of how it can become a winner in the SCF context. Here, there is a clear lack of academic work. However, one may draw from the literature on relationship banking (e.g., Boot, 2000), which suggests that a closer collaboration (both scope and depth) may lead to a benefit for the bank but not necessarily for the involved corporate client due to lock-in effects (e.g., high switching costs). Due to better collaboration, the bank may acquire more information, which could lead to a reduction in credit risk that in turn may or may not be passed on to the end customer in the form of lower interest rates. An important source of a WWS that a FI can generate refers to the interest rate arbitrage (Seifert and Seifert, 2011). This form of "giving credit support” occurs when either a supplier or buyer can get access to loan facilities at the same (or similar) rate of the better-rated buyer or supplier. While a supplier may benefit from a lower cost of credit, the buyer can stretch the payment terms, leading to positive effects in the cash flow statement and potentially a WWS for both parties.

\subsection{Conclusion on the literature review}

While WWS can often be associated with mutual collaboration and intensified information sharing in strategic supplier-buyer relationships, there is no general consensus as to whether a WWS should lead to a measurable financial profit. Nevertheless, the win-win condition from Giannoccaro and Pontrandolfo (2004), which implied that every SCA should derive a profit from a SC initiative, shall serve as a guideline when investigating our SCF model. Inferring from the literature above, it is unlikely, however, that all parties involved in a SC initiative can derive similar benefits. 
The second part of the literature review has focused on SCF-related literature. It was shown that WWS in SCF come along with optimized WC (as benefits). The optimization of WC encompasses (i) the attainment of an 'adequate' level on net working capital, (ii) the reduction of the 'handling costs' to administer the net working capital, and (iii) the minimization of risks relating to net working capital. While Hofmann and Belin (2011) found in their calculations that SCF can lead to tangible net benefits for both the suppliers and buyers, they did not address the question of to what extent the FI can also derive a benefit. Naturally, one could assume that if the FI is not able to derive a profit from these services, then these institutions would not offer SCF solutions. In the further set-up of the model, where an export financing platform is investigated, this paper aims to extend this perspective and accordingly investigates whether the FI could be a third winner in the SCF context. Also, the literature on SCF has not concretely characterized a WWS and how the benefits derived should be shared between the involved actors.

\section{Concept}

\subsection{Supply chain finance platforms}

SCF platforms are based on collaborative arrangements between network members that include - in addition to the pure inside internal format - an external party (either a service provider or FI), which provides funding to one or multiple firms in the network. The spectrum of instruments is broad and ranges from "approval to pay solutions” to "open account platforms," "reverse factoring," and more. Common to all these approaches is the involvement of an third party provider in order to foster the information flow, to enhance transparency and to mitigate risks. Even though financing is not obtained directly within the collaborative entity, this form of financing is still considered internal (to the network) in the sense that either a supplier or buyer can indirectly provide funding to its network partners at more favorable terms (Seifert and Seifert, 2011).

In general, three financing platform mechanisms can be distinguished. The export financing platform focuses on AR, whereas the import-oriented solution centers on AP. Both of them support transactions based on letters of credit $(\mathrm{L} / \mathrm{C})$ or open accounts $(\mathrm{O} / \mathrm{A}) .^{2}$ The third option is closely linked to inventory financing and is considered to have the least impact and potential to optimize working capital (Hofmann, 2009).

Looking purely at the financing mechanism, Hofmann and Belin (2011) note that platform solutions somewhat resemble those termed as more "traditional" in the SCF arena (e.g., reverse

\footnotetext{
${ }^{2}$ According to SWIFT (2012), 80\% of global trade occurs on O/A terms.
} 
factoring or invoice discounting). However, platform-based financing mechanisms tend to be more long-term oriented since considerable investments (e.g., IT and training of staff) need to be made by the participating institutions. Camerinelli (2009a, pp. 86) mentions that the "novelty" of these financing forms is characterized by the customized web portals that deliver realtime data to all actors in the FSC. These data include not only pure debit or credit instructions but also track further details about the physical movement of the goods (e.g., shipment information). Also, FIs are interested in this information, since the closer they can monitor the transaction, the better they can optimize credit risk.

For the purpose of this paper, the discussion of SCF platforms will now focus on the case where the supplying exporter (FC) is characterized as the initiating party (AR platform). Such a SCF solution has an advantage to the supplier in that a host of individual invoices sent to the buyers can be aggregated and processed through one single platform. The FI provides funding to the exporter (FC) at a mutually agreed date based on the outstanding receivables. The receivable format (e.g., whether it is based on a confirmed invoice or bill of lading) has an influence on the financing terms and the amount of finance received by the supplier. In a simplified manner, Figure 2 shows the functional principle, where the exporting FC (supplier) is the initiator of the financing initiative and promotes its accounts receivable platform (ARP) to its buyers.

Figure 2: Accounts receivable platform program (export financing)



The most important steps for a transaction intermediated by means of an ARP program can be summarized as follows:

1. The first step is always that buyers place orders with the respective supplier, and goods are shipped depending on the agreed terms (either "open account” (O/A) or "letter of credit” (L/C)) between the network partners. Here, the SCF platform does not have a specific role, though it would be desirable that the order's information would be directly 
translated to the platform so that the intermediate steps in the delivery process can be monitored.

2. The invoice data for the different buyers need to be uploaded to the platform by the supplier on a recurring basis (e.g., daily).

3. Buyers are requested to access the invoice data daily, validate the respective amounts with their own bookkeeping system, and eventually approve the invoices on the platform.

4. The platform is then able to match the data with the approved invoices of the buyers. Information about the creditworthiness (e.g., transaction history and ratings) is then made available to the FI (in case the FI is not the owner of the platform). The FI verifies the data and determines if funding can be granted to the supplier and at which terms.

5. The supplier is informed by the FI about the authorization of the invoice data and is able to access the funds (minus a margin) from the FI at a predefined date.

6. Buyers pay the invoice value to the FI plus a funding fee. Additional costs (e.g., transaction fees) may also be levied to the buyers.

\subsection{A case for triple win}

In order to address the initial research objective, the questions arise, on the one hand, which role a FI would take on in the supply chain and, on the other hand, what such a triple-win situation could look like. Up to this point, it has been argued that suppliers and buyers collaborate in a network and that FIs are part of the FSC. But from the viewpoint of the supplier or buyer, there is no clear indication in the academic literature that a FI should be a part of this closer entity yet. Though not directly connected to the SCF arena, Chua and Mahama (2007, p. 52) suggest a whole "action net," including external parties (potentially also FIs) that need to be considered in a supplier-buyer relationship. They note that the dynamics of a collaborative effort can significantly change if an external party joins or leaves this "network”. In case of ARP, this network can be ascribed as the "arena of supply chain finance”.

The triple-win idea that will be further investigated in this paper concerns platform approaches. From a banks perspective, one can note that a SCF solution is only successful if the FC can motivate multiple network partners to participate and if transactions are carried out on a regular basis. Recurring transactions will allow FIs to learn more about the creditworthiness of the buyers and may lead to more beneficial financing terms for both suppliers and buyers in the long term. The supplier reduces AR and is able to access funds earlier. The buyer can stretch its AP, and the FI may extend credit facilities to the network partners. Triple-win situations are likely to occur in this financing alternative if the bank owns the platform by itself. These FIs 
aim to provide a holistic trade finance solution by capturing the full flow of information (physical and financial), which will allow them to get a better picture of the underlying (credit) risks (Camerinelli, 2009a). Finally, it will have a direct effect on the balance sheet of the FI, since loans are provided to the SCF solution participants. To conclude, the revenues derived by the involved parties have to exceed the costs that occur by engaging in a network financing alternative (= positive net benefit). Even though FIs or other external service providers may play a role in all of the alternatives, ARP programs seem to have great potential to achieve a TWS.

The analysis that follows next partially builds on the work of Hofmann and Belin (2011), who derived the net benefit for both suppliers and buyers that engage in a SCF solution. Their approach will be extended, on the one hand, by taking into account the FI perspective and, on the other hand, by specifically focusing on one SCF solutions, the ARP program. By looking at possible trade flows in a cross-border FSC, the model aims to identify situations under which SCF arrangements are beneficial and investigates whether a triple-win situation-a state in which all SCAs derive a positive net benefit-are feasible. In addition to the derivation of the net benefit $\left(\pi_{i}\right)$ of the SCF initiative for the involved actors (from a single actor viewpoint), the model provides insights to the following overarching questions:

- Whether and under what situations a net benefit to the FSC implies simultaneously a net benefit for all participating actors in the SCF initiative? And if so, how are the benefits shared in the FSC?

- How the average payment balance $\left(\boldsymbol{A} P \boldsymbol{B}^{*}\right)$ influences the decision of the individual actors to participate or refrain from participating in a SCF initiative?

\section{Model}

\subsection{Conceptualization}

Considering a FSC with three SCAs during one period $t$, the ARP program is characterized by one supplier (S), $n$ buyers (B), and one financial institution (FI). The formula $A R_{S} / A P_{B}$ denotes the average payment balance in the FSC between one supplier $\left(A R_{S}\right)$ and one buyer $\left(A P_{B}\right)$ . ${ }^{3}$ The supplier, characterized as the initiating firm (FC) of the SCF solution, enters into a receivables purchasing agreement with the FI and has to make sure that buyers are also willing to participate in this initiative. The supplier (FC) is assumed to be located in an OECD country, whereas its customers (buyers) are situated in a non-OECD state. Also the FI that is intermediating the trade is domiciled in an OECD country. All buyers place the same number of orders

\footnotetext{
${ }^{3}$ The average we are referring to is actually a time-average obtained as an arithmetic average in the attendant period.
} 
(s) for which one financial transaction is required, respectively. The FI is willing to provide working capital in the amount of $A R_{S} / A P_{B} \cdot s \cdot n$ (the total payment balance in the FSC) in each time period $t$ both to suppliers and buyers at terms that are specified later. The total payment balance can also be characterized as the working capital needs in the FSC by stating that it is the amount of capital that (i) the supplier (FC) needs in order to continue the operations and that (ii) the buyers need to fulfill their financial obligations. The characterization (variables) of the trade flows are summarized in Table 1.

Table 1: Characterization of trade flows (variables)

\begin{tabular}{|c|l|}
\hline$A R_{\mathrm{S}} \boldsymbol{A} P_{\mathrm{B}}, A P B$ & Average payment balance (invoice value) between one supplier and one buyer in period $\boldsymbol{t}$ \\
\hline $\boldsymbol{s}$ & Number of transactions placed in period $\boldsymbol{t}$ by one buyer \\
\hline $\boldsymbol{n}$ & Number of buyers participating in the ARP program \\
\hline
\end{tabular}

\subsection{FSC parameters}

A first relevant parameter is the risk-adjusted funding rate $\left(i_{i}\right)$, which is dependent on the payment term, the total transaction volume, and an exogenous risk factor $\beta_{i}$ for all three actors. The payments without the SCF initiative are denoted by $D_{S O_{N S C F}}$ and $D P O_{N S C F}$, while their counterparts with the SCF initiative are denoted by DSOSCF and DPOSCF. Servicing fees $\left(\omega_{S}\right)$ are charged by the FI to the supplier for the usage of the platform and represent revenue to the FI. Besides the required fixed costs needed for the IT infrastructure, it is assumed that all participants in the ARP program incur certain set-up costs $\left(\kappa_{i}\right)$ for the SCF solution. Furthermore, for every transaction $(s)$ in period $t$, both suppliers and buyers shall pay a processing fee $\left(v_{i}\right)$ to the FI (independent of the transaction volume). Finally, common to all actors in the FSC is the investment $\left(I_{i}\right)$ needed to participate in a SCF solution (treated as fixed cost later on). However, for the buyers as well as for the FI, it is assumed that only a fraction $\left(\theta_{i}\right)$ of the required investment $I_{i}$ can actually be allocated to the single SCF initiative considered in this model.

The parameters included in Tables 2, 3, and 4, which are labeled with $\oplus$, are "supporting parameters” and cannot be quantified with a real value by themselves (monetary value, days, or percentage), but rather refer to other parameters and indicate how they might potentially change in case more participants join the program or more transactions are handled by means of the SCF initiative.

Table 2: FSC parameters

$i_{i} \quad$ Risk-adjusted funding fee, where $i \in\{S, B\}$ for the supplier and buyer 


\begin{tabular}{|c|l|}
\hline$D S O_{N S C F, S C F}$ & Payment term for supplier $(D S O)$ and buyers $(D P O)$ without and with a SCF solution \\
$D P O_{N S C F, S C F}$ & Exogenous risk factor, where $i \in\{S, B\}$ for the supplier and buyer \\
\hline$\beta_{i}$ & $\begin{array}{l}\text { Supporting parameter indicating how funding costs decrease with more buyers/ transactions } \\
\text { in the model }\end{array}$ \\
\hline$y^{\oplus}$ & SCF service fee for the supplier \\
\hline$\omega_{S}$ & Set-up costs, where $i \in\{S, B, F I\}$ for the supplier, buyer, and the FI \\
\hline$\kappa_{i}$ & $\begin{array}{l}\text { Supporting parameter indicating how set-up costs decrease with more buyers/transactions in } \\
\text { the model }\end{array}$ \\
\hline$\sigma^{\oplus}$ & $\begin{array}{l}\text { Processing fee for every SCF transaction }(s) \text {, where } i \in\{S, B, F I\} \text { for the supplier, buyer, } \\
\text { and the FI }\end{array}$ \\
\hline$v_{i}$ & $\begin{array}{l}\text { Supporting parameter indicating how transaction costs decrease with more buyers/ transac- } \\
\text { tions in the model }\end{array}$ \\
\hline$\mu^{\oplus}$ & $\begin{array}{l}\text { Investment to participate in the SCF solution, where } i \in\{S, B, F I\} \text { for the supplier, buyer, } \\
\text { and the FI }\end{array}$ \\
\hline $\boldsymbol{I}_{\boldsymbol{i}}$ & $\begin{array}{l}\text { Fraction of SCF investment }\left(\boldsymbol{I}_{\boldsymbol{i}}\right) \text { for non-focal companies and the FI attributable to the re- } \\
\text { spective SCF solution } i \in\{B, F I\} \text { for the buyer and the FI }\end{array}$ \\
\hline$\theta_{i}$ &
\end{tabular}

The weighted average cost of capital for suppliers and buyers is indicated by $W A C C_{i}$. It is an important parameter in order to derive $\boldsymbol{\Delta} \boldsymbol{W} \boldsymbol{C}_{i}$ (unlocked working capital). Furthermore, $\alpha_{i}$ refers to a fixed amount that can be saved (administrative benefit) when choosing to participate in a SCF solution. The loss ratio $\left(\gamma_{s}\right)$ of a supplier refers to a fraction of the total transaction volume that is expected to be uncollectable (e.g., due to the default of a buyer). This risk is only supplier centric and can be "outsourced" to the FI that will take over this risk.

Table 3: Parameters specific to suppliers and buyers

\begin{tabular}{|c|l|}
\hline$W A C C_{i}$ & Weighted average cost of capital, where $i \in\{S B\}$ for the supplier and buyer \\
\hline$\Delta W C_{i}$ & Unlocked working capital, where $i \in\{S B\}$ for the supplier and buyer \\
\hline$w^{\oplus}$ & $\begin{array}{l}\text { Supporting parameter (for the supplier) indicating how the unlocked working capital decreases } \\
\text { with more buyers in the model }\end{array}$ \\
\hline$\alpha_{i}$ & Administrative benefit for every transaction (s) where $i \in\{S B\}$ for the supplier and buyer \\
\hline$\tau^{\oplus}$ & $\begin{array}{l}\text { Supporting parameter indicating how the administrative benefit decreases or increases with } \\
\text { more buyers with respect to transactions in the model }\end{array}$ \\
\hline$\gamma_{S}$ & Supplier's loss ratio \\
\hline$\phi^{\oplus}$ & Supporting parameter indicating how the risk benefit increases with more buyers in the model \\
\hline
\end{tabular}

Banks are assumed to access funds at $r_{f}$ and to pay a securitization fee $\left(z_{F I}\right)$ depending on the time and the amount of credit granted as well as the risk factor of the buyer $\left(\beta_{B}\right)$. By directly financing the ARP program, the FI will forego a fraction of other interest income $\left(l_{F I}\right)$ that could otherwise have been generated with traditional loan facilities. The parameter $c_{F I}$ denotes 
a fraction of the total transaction volume as the income generated due to cross selling additional services to the FC (Camerinelli, 2009a).

\section{Table 4: Parameters specific to financial institutions}

\begin{tabular}{|l|l|}
\hline$r_{\boldsymbol{f}}$ & Risk-free rate \\
\hline$Z_{F I}$ & Reinsurance fee for SCF credit facility granted \\
\hline$\chi^{\oplus}$ & $\begin{array}{l}\text { Supporting parameter indicating how the reinsurance fee decreases with more transactions with } \\
\text { respect to buyers in the model }\end{array}$ \\
\hline$I_{F I}$ & Interest income foregone from traditional loan facilities \\
\hline$C_{F I}$ & Cross-selling income \\
\hline$\lambda^{\oplus}$ & $\begin{array}{l}\text { Supporting parameter indicating how the cross-selling income decreases with more buyers in the } \\
\text { model }\end{array}$ \\
\hline
\end{tabular}


The general model assumptions can be summarized as follows:

1. The model does not entirely follow the perfect capital market theory as outlined by Miller and Modigliani (1958). By engaging in a SCF solution (ARP program), a firm may create additional value either for itself, a counterparty, or the FSC as such. There are, however, model components that are closely aligned with a perfect market (e.g., no information asymmetry, no credit rationing, and unlimited access to financial markets for FIs at $r_{f}$ ).

2. Homogenous buyers: They place the same amount of orders with an identical average invoice value. Also, the risk factor $\left(\beta_{B}\right)$ is similar for all buyers.

3. Access to bank financing: In the ARP program, the supplier (FC) possesses a better rating than the buyers $\left(\beta_{S} \leq \beta_{B}\right)$, and interest rates in the supplier's country (OECD) are lower than in the buyer's non-OECD home market $\left(i_{S}<i_{B}\right)$. The interest rates are set as external parameters and do not reflect the cost of capital but rather the more general terms of debt financing in OECD and non-OECD markets, respectively. This is also the reason why the CAPM model is not applied here, since it is a market-driven approach that would be challenging to incorporate into the net-benefit calculation.

4. No defaults occur in the FSC. However, in order to derive a net benefit of the SCF initiative to the supplier, the model allows accounting for a "risk benefit" (FC can shift the default risk of its buyers to the FI, which then has to factor in this risk component).

5. Capital-constrained suppliers and buyers: They are only willing to participate in the ARP program if a positive net benefit can be derived (other funding options might also exist).

6. Invoicing will take place in USD, and there is no currency risk.

\subsection{General model specifications}

When deriving the net benefit of a SCA, the model will distinguish between a revenue function $\left(R_{i}\right)$ and a cost function $\left(C_{i}\right)$. However, the revenue from a SCF initiative does not necessarily imply a direct positive net cash inflow, but it could also refer to unlocked working capital that is derived based on the cost of capital (WACC) and is assumed to have a positive long-term effect for the firm. However, when looking at the funding of SCF solutions, the model does not take into consideration the cost of capital, but rather the actual cost of debt (funding fees adjusted for a risk factor), since this is direct cash outflow that can be specifically allocated to debt financing expenses. 
Both for suppliers and buyers, the derivation of the net benefit mainly follows the approach of Hofmann and Belin 20114:

Net benefit $\left(\pi_{S, B}\right)=$ Risk benefit + Unlocked WC (see below) + Administrative benefits

$$
\begin{aligned}
& \text { - Funding fees - Servic fees - Transaction-based fees } \\
& \text { - Set up costs - Initial investment (fixed costs). }
\end{aligned}
$$

With respect to the forthcoming model discussion, we expect that a supplier or buyer unlocks WC $\left(\Delta \boldsymbol{W C}_{i} \geq \mathbf{0}\right)$ in any case if they choose to participate in a SCF solution. According to Hofmann and Belin (2011, p. 61), the change in WC for an importer (in our case the FC) can be described as follows:

Unlocked WC $\left(\Delta W C_{i}\right)=$ Importer's WACC $\cdot((\mathrm{DPO}$ of importer without an SCF solution - DPO of importer with an SCF solution) / 365) · AP.

To derive the net benefit of a FI, the model will investigate how the revenue streams might get affected when a FI chooses to participate in a SCF solution. The overall optimization problem according to net benefit can be described as follows:

$$
\begin{aligned}
\text { Net benefit }\left(\pi_{F I}\right)= & \text { Funding margin }+ \text { SCF revenues (service fees, transaction fees, cross-selling income) } \\
& - \text { Refinancing and securitization fees }- \text { Interest income foregone } \\
& - \text { Transaction-based fees }- \text { Set-up costs }- \text { Initial investment (fixed costs). }
\end{aligned}
$$

Where a parameter (e.g., $\left.i_{i}, \gamma_{S}, z_{F I}\right)$ is dependent on the firm specific risk $\left(\beta_{i}\right)$, it is assumed in accordance to common capital market theory and as discussed in Copeland et al. (2005) that $\beta_{i} \leq 1$ refers to a firm with below-average market risk, $\beta_{i}=1$ refers to a firm with average market risk, and $\beta_{i} \geq 1$ refers to a firm with above-average risk.

\subsection{Supplier net benefit}

In this subsection, we outline the mathematical derivation of the net benefit for the supplier (FC) and introduce the corresponding revenue and cost functions both in mathematical and simplified non-analytic terms.

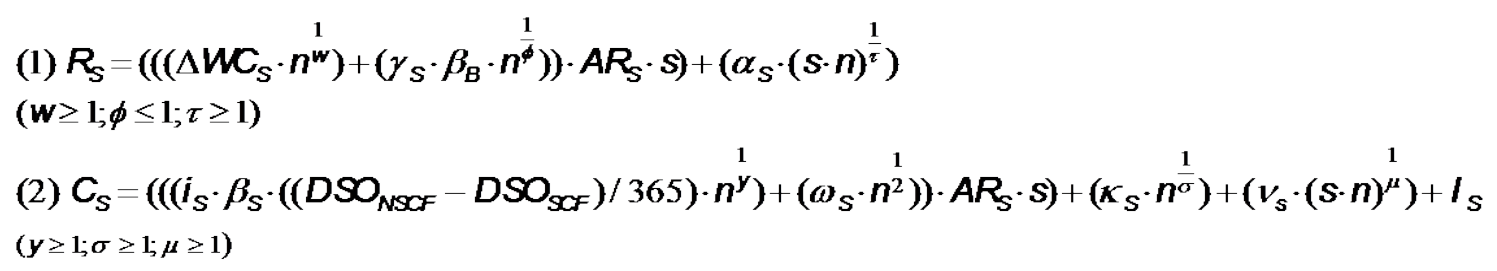

\footnotetext{
${ }^{4}$ The two components "risk benefit" and "servicing fee” are relevant only for the supplier (FC).
} 
Supplier revenue $\left(\mathrm{R}_{S}\right)=((($ Unlocked WC $\cdot$ \#buyers $)+($ Risk benefit $\cdot$ Risk factor $\cdot$ \#buyers $))$

- AR · \#transactions) + (Admin. benefit · \#transactions · \#buyers).

Supplier costs $\left(\mathrm{C}_{\mathrm{S}}\right) \quad=((($ Funding rate OECD $\cdot$ Risk factor $\cdot($ DSO reduction/365) $\cdot$ \#buyers $)$

$+($ Service fee $\cdot$ \#buyers $)) \cdot$ AR · \#transactions $)+($ Set-up costs ·\#buyers $)$

+ (Transaction fee $\cdot \#$ transactions ·\#buyers $)+$ Initial investment.

With respect to the revenue function (1), one can note a linear dependence between both the risk benefit $\left(\gamma_{S}\right)$ as well as the change in working capital $\left(\Delta W C_{s}\right)$ towards the payment balance of one buyer. This seems logical since the supplier is able to gain more if it can increase the transaction volume with a single buyer. Furthermore, with more buyers joining the ARP program, the derived revenue (per buyer) is subject to change. In the model, it is assumed that the benefit from unlocking WC decreases slightly ${ }^{5}$ and the risk benefit becomes larger when more buyers join the SCF solution (see parameters $\boldsymbol{W}$ and $\phi$ in function 1, respectively). This can be justified, since the supplier's risk ${ }^{6}$ is outsourced to the FI and therefore the revenue is assumed to grow faster in the model when the supplier does not need to bear this risk. The last component of the revenue function deals with the administrative benefit, which is both dependent on the transaction frequency as well as on the number of participants in the ARP program. The parameter $\tau$ will indicate that the administrative benefit somewhat levels out as more buyers join and hence transaction volume increases.

Looking at the costs incurred by the supplier in function (2), it depends on the negotiation power of the supplier towards the FI whether it may get access to the funds immediately $\left(D S O_{S C F}=0\right)$ or at a predefined date $\left(D S O_{S C F}>0\right)$ for which it incurs financing costs over the time period $D S O_{N S C F}-D S O_{S C F}$. We assume a linear relationship between these costs and the total transaction volume per buyer. However, with more buyers joining the platform, the supplier may get a discount on the interest rate, since the risk for the FI will be more diversified (see parameter $y)$. This could allow the FI to price the loans at more favorable rates for the supplier. Furthermore, the servicing fee $\left(\omega_{s}\right)$ to be paid to the FI depends on the transaction volume of one buyer and decreases when more buyers join the platform (see $n^{\frac{1}{2}}$ ). The same applies for the set-up expenses $\left(\kappa_{s}\right)$ that arise each time a new buyer can be convinced to join the program as well as to the fees charged to the supplier based on the transaction frequency (see parameters $\sigma$ and $\mu$ in function (2) respectively). Finally the required investment has to be accounted for.

\footnotetext{
${ }^{5} \boldsymbol{W}$ is set close to 1 . The gain from unlocking WC might not be as efficiently allocated within the firm when more buyers join the platform and accordingly, the total export volume increases.

${ }^{6}$ The risk of non-performing buyers, from which the supplier is not able to collect the payment balance.
} 
Combining (1) and (2), the net benefit of the ARP program simplifies to $\pi_{s}=R_{S}-C_{S}$. The supplier breaks even with the ARP program when $\pi_{s}=0$ and solving for $n *$ yields the required number of buyers necessary to make the ARP program profitable. Finally, function (3) highlights the average payment balance $\left(A R_{S}{ }^{*}\right)$ necessary for a profitable ARP program to the supplier (setting $\pi_{S}=0$ and solving for $A R_{S}^{*}$ ). It is only profitable for the supplier to handle a stream of transactions through the ARP mechanism if the average invoice amount exceeds $A R_{S}^{*}$ given a fixed number of buyers in the base scenario.

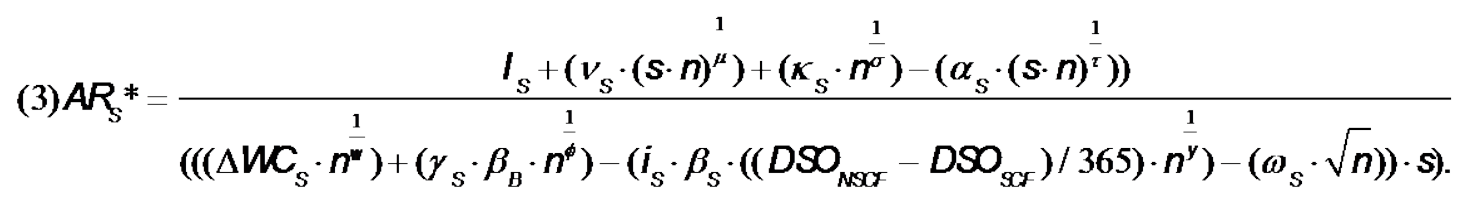

\subsection{Buyer net benefit}

Shifting the focus to the buyer side, we outline the derivation of the net benefit for the corresponding SCAs in this subsection.

$$
\begin{aligned}
(4) R_{B} & =\left(\left(\left(\Delta W C_{B} \cdot s\right)+\left(\beta_{B} \cdot\left(i_{B}-i_{S}\right) \cdot\left(\left(D P O_{S C F}-D P O_{N S C F}\right) / 365\right) \cdot s^{y}\right) \cdot A P_{B}\right)+\left(\alpha_{B} \cdot s^{\frac{1}{\tau}}\right) .\right. \\
(y & \geq 1 ; \tau \leq 1) \\
(5) C_{B} & \left.=\left(\beta_{B} \cdot i_{S} \cdot\left(\left(D P O_{S C F}-D P O_{N S C F}\right) / 365\right)\right) \cdot A P_{B} \cdot s^{\frac{1}{y}}\right)+\left(\kappa_{B} \cdot s^{\frac{1}{\sigma}}\right)+\left(v_{B} \cdot s^{\frac{1}{\mu}}\right)+\left(I_{B} \cdot \theta_{B}\right) . \\
(y & \geq 1 ; \sigma \geq 1 ; \mu \geq 1)
\end{aligned}
$$

Buyer revenue $\left(\mathrm{R}_{B}\right)=(($ Unlocked WC $\cdot$ \#transactions $)+($ Risk factor

· Funding rate difference non-OECD vs. OECD · (DPOextension/365))

- \#transactions · AP) + (Admin. benefit · \#transactions).

Buyer costs $\left(\mathrm{C}_{B}\right) \quad=($ Risk factor $\cdot$ Funding rate non-OECD $\cdot($ DPO extension/365 $) \cdot A P \cdot$ \#transactions $)$

+ (Set-up costs · \#transactions) + (Transaction fee · \#transactions)

$+($ Initial investment $\cdot$ Allocation factor).

As can be observed in function (4), a buyer will gain from the ARP program by unlocking WC depending on how long the payment terms can be extended. In contrast to the supplier, it is assumed that this parameter is in linear dependence with the transaction volume (higher efficiency to allocate unlocked capital). Furthermore, it is assumed that buyers obtain financing from the supplier's bank in an OECD domicile. Therefore, they are able to secure funding at more favorable terms than in their "home market". ${ }^{7}$ This benefit is indicated by $\beta_{B} \cdot\left(i_{B}-i_{S}\right)$.

\footnotetext{
${ }^{7}$ Note: There are alternative approaches in place, where non-OECD banks in the "home markets" of the buyers provide the financing. In this case, it is argued that the bank knows the buyers and affiliated business risks well. Together with guarantees and market insights provided by the vendor, favorable terms are also feasible.
} 
The parameter $y$ accounts for the fact that the interest rate benefit increases, since the costs for the funding decreases as more transactions are handled through the platform mechanism. Similar to the supplier case, one can argue that the FI is able to offer more favorable funding terms when the buyer's transaction frequency increases, and therefore the operations (including order and payment behavior) become more transparent to the bank, allowing them to better assess the risk. In contrast to the supplier case, the parameter $\tau$ is set as such that administrative benefit increases as more transactions occur through the platform.

Focusing on the cost side, function (5) looks similar to the supplier case previously introduced, except that buyers do incur set-up costs $\left(\kappa_{B}\right)$ based on the number of transactions. Furthermore, and in contrast to the supplier, no service fees are levied by the FI to the non-focal companies (Hofmann and Belin, 2011). However, this model incorporates a transaction-dependent fee to be incurred by the buyers for every invoice processed $\left(v_{B}\right)$. Both the set-up costs and the transaction based fees are assumed to decrease with a growing transaction volume (see parameters $\sigma$ and $\mu$ in function (5), respectively). Additionally, the only fixed cost is the required investment $\left(I_{B} * \theta_{B}\right)$.

Since all buyers have by definition the same characteristics and transaction frequencies, the total net benefit for all buyers in the model can be expressed by

$$
\text { (6) } \sum_{i=n} \pi_{i}=\left(R_{B}-C_{B}\right) \cdot n
$$

It follows that if one buyer benefits from the ARP program, all buyers will be in the same favorable position. The minimum average payment balance $A P_{B} *$ for a single buyer can be derived in the same way as in the previous chapter for the supplier case (see appendix for mathematical derivation).

\subsection{Financial institution net benefit}

The derivation of the net benefit for the FI relies to a large extent on the previously described calculations as can be seen in the following formulas: 


$$
\begin{aligned}
(7) R_{F I}= & \left(\left(\left(i_{S} \cdot \beta_{B} \cdot\left(\left(D S O_{N S C F}-D S O_{S C F}\right) / 365\right) \cdot s \cdot n^{\frac{1}{y}}\right)+\left(i_{S} \cdot \beta_{B} \cdot\left(\left(D P O_{S C F}-D P O_{N S C F}\right) / 365\right)\right.\right.\right. \\
& \left.\left.\left.\frac{1}{\frac{1}{y}} \cdot n\right)+\left(\omega_{S} \cdot s \cdot \sqrt{n}\right)+\left(c_{F I} \cdot s \cdot n^{\frac{1}{\lambda}}\right)\right) \cdot A P B\right)+\left(v_{S} \cdot(n \cdot s)^{\frac{1}{\mu}}\right)+\left(v_{B} \cdot n \cdot s^{\frac{1}{\mu}}\right) . \\
y \geq & 1 ; \lambda \geq 1 ; \mu \geq 1 \\
(8) C_{F I}= & \left(r_{f} \cdot n\right)+\left(z_{F I} \cdot i_{S} \cdot \beta_{B} \cdot\left(\left(D P O_{S C F}-D S O_{S C F}\right) / 365\right) \cdot n^{\frac{1}{\chi}}\right)+\left(l_{F I} \cdot \beta_{S}\right. \\
& \left.\left.\left.\cdot\left(\left(D S O_{N S C F}-D S O_{S C F}\right) / 365\right) \cdot \sqrt{n}\right)\right) \cdot A P B \cdot s\right)+\left(v_{F I} \cdot(s \cdot n)^{\frac{1}{\mu}}\right)+\left(\kappa_{F I} \cdot n^{\frac{1}{\sigma}}\right)+\left(I_{F I} \cdot \theta_{F I}\right) . \\
\chi & \geq 1 ; \mu \geq 1 ; \sigma \geq 1
\end{aligned}
$$

FI revenue $\left(\mathrm{R}_{\mathrm{FI}}\right)=(($ Interest income attr. to supplier + Interest income attr. to buyers

+ Service fee income + Cross-selling income) $\cdot$ \#transactions · \#buyers · APB)

+ (Transaction fees from supplier and buyers · \#transactions · \#buyers).

FI costs $\left(\mathrm{C}_{\mathrm{FI}}\right) \quad=(($ Risk-free rate $\cdot$ \#buyers $)+($ securitization fee $\cdot$ funding rate supplier

- Risk-factor buyer · Loan tenor · \#buyers) + (Interest income foregone

- Risk-factor supplier · DSO extension ·\#buyers) $\cdot$ APB · \#transactions)

+ (Transaction fees · \#transactions · \#buyers) + (Set-up costs · \#buyers)

+ (Initial investment · Allocation factor).

Function (7) reveals that for the FI, the revenue from the ARP program is mainly constituted of the funding margin $\left(i_{S} ; i_{B}\right)$ as well as of the income from servicing and transaction fees that were earlier described in the supplier and buyer context, respectively. Accordingly, the shape of the FI revenue function is mainly determined by the cost functions of the supplier and the participating buyers. The revenue derived through the pure funding activities (funding spread) increases linearly with the average invoice amount. Cross-selling activity $\left(c_{F I}\right)$ is the only parameter in the function that is not directly connected to the supplier's or buyer's cost function. Since the FI has closer ties to the FC rather than to the buyers, it accordingly aims to offer further services to the FC. However, this additional income generated will most likely decrease at some point. On the one hand, the model assumes that when more transactions with a higher invoice value are handled through the platform, the FI can extract more cross-selling income from the supplier. On the other hand, when more buyers join the program, the FI cannot linearly increase this revenue (see parameter $\lambda$ above). This is due to the fact that when initially setting-up the ARP program, the chance of selling further services is higher, e.g., through more in depth-negotiations, than later on when more buyers join the platform (at a later stage, the SCF initiative may become an ordinary business activity and less intensive communication may occur between the FC and the FI). Furthermore, (7) indicates that the income generated from the transaction-based fees levied on the suppliers decreases faster than those for the buyers. This can be justified, since the FI is faced with multiple buyers for which it can each charge the same amount. 
Looking at the cost formula (8), the FI accesses funds at the market rate $r_{f}$ and needs to account for a securitization fee $\left(z_{F I}\right)$ during the whole time frame of the outstanding loan. Here, the market rate for securitizing these loans may become more favorable when more buyers join the program, since part of the risk may be diversified away (see parameter $\chi$ above). If the FI grants more SCF loans, it will also likely lose other business. The loan income foregone, however, is only considered with regards to the payment term optimization of the supplier $\left(D S O_{N S C F}-D S O_{S C F}\right)$. This is mainly because the FC is supposed to have closer ties to the FI before

setting up the ARP program. This needs to be accounted for by the term $(\sqrt{n})$. Furthermore, the FI incurs transaction specific costs (similar to the buyer and supplier) that could be attributed to either internal system maintenance costs or outsourcing fees, for which the FI incurs costs based on the number of transactions handled through the platform. Similar to the supplier, the FI incurs set-up costs $\left(\kappa_{F I}\right)$ for each buyer joining the platform (e.g., contracting costs and monitoring), which are supposed to be optimized with more participants in the SCF solution. The last two cost components are supposed to decrease at a rate of $1 / \mu$ and $1 / \sigma$, respectively. Again, the mathematical derivation of the minimum average payment $A P B^{*}$ balance for the FI is outlined in the appendix.

\section{Analysis}

\subsection{Base scenario}

In order to support the derived calculations with real figures, a base scenario as well as the parameter values are introduced (Table 5): The average invoice amount $\left(A R_{S} / A P_{B}\right)$ is set to $\$ 10,000,{ }^{8}$ and the number of transactions (s) for one buyer is assumed to be 50 . Furthermore, it is expected in the base scenario that 60 buyers $(n)$ participate on average in the SCF solution, and the FC may expand the ARP program to a maximum of 100 participants. This translates to an average purchasing volume of $\$ 500,000$ for one buyer and for the FC to a potential export volume of $\$ 50$ million.

In accordance with the model of Hofmann and Belin (2011), a funding fee $\left(\boldsymbol{i}_{i}\right)$ of $3 \%$ is applied for the FC. For the buyers, however, it is assumed that they face an interest rate that is twice as high (6\%) compared to the FC. ${ }^{9}$ Also, the firm specific risk factor $\left(\beta_{i}\right)$ is considerably

\footnotetext{
${ }^{8}$ Hofmann and Belin (2011, p. 57) use an average invoice value of \$5,392.

${ }^{9}$ Similarly, Hofmann and Belin (2011) assume the WACC for a non-OECD buyer to be almost twice as high compared to the FC in the OECD location.
} 
higher for the buyer. Even though the buyers will not access funding at $\boldsymbol{i}_{\boldsymbol{B}}$ but rather at $\boldsymbol{i}_{\mathrm{S}}$, this proxy is used to quantify the net benefit of the SCF initiative.

Table 5: Parameter values for ARP program (base scenario)

\begin{tabular}{|c|c|c|c|c|c|c|}
\hline Parameter / SCA & FC & Buyers & $\begin{array}{c}\text { Parameter / } \\
\text { SCA }\end{array}$ & FC & Buyers & FI \\
\hline$i_{i}$ & $3 \%$ & $6 \%$ & $v_{i}$ & $\$ 20$ & $\$ 20$ & $\$ 40$ \\
\hline$W A C C_{i}$ & $8 \%$ & $15 \%$ & $\kappa_{i}$ & $\$ 13,000$ & $\$ 600$ & $\$ 8,000$ \\
\hline$\beta_{i}$ & 1 & 1.7 & $r_{f}$ & $\mathrm{n} / \mathrm{a}$ & $\mathrm{n} / \mathrm{a}$ & $0.3 \%$ \\
\hline $\begin{array}{l}D S O_{S C F} \\
D P O_{S C F}\end{array}$ & 3 & 80 & $Z_{F I}$ & $\mathrm{n} / \mathrm{a}$ & $\mathrm{n} / \mathrm{a}$ & 0.3 \\
\hline $\begin{array}{l}D S O_{\mathrm{NSCF}} \\
D P O_{\mathrm{NSCF}}\end{array}$ & 60 & 45 & $l_{F I}$ & $\mathrm{n} / \mathrm{a}$ & $\mathrm{n} / \mathrm{a}$ & $1 \%$ \\
\hline$\alpha_{i}$ & 20 & 20 & $C_{F I}$ & $\mathrm{n} / \mathrm{a}$ & $\mathrm{n} / \mathrm{a}$ & $1 \%$ \\
\hline$\omega_{i}$ & $0.8 \%$ & $0.8 \%$ & $I_{i}$ & $\$ 50,000$ & $\$ 20,000$ & $\$ 5,000,000$ \\
\hline$\overline{\gamma_{S}}$ & $0.4 \%$ & $\mathrm{n} / \mathrm{a}$ & $\theta_{i}$ & $\mathrm{n} / \mathrm{a}$ & $13 \%$ & $1 \%$ \\
\hline
\end{tabular}

The extension of the payment term $\left(D P O_{S C F}-D P O_{N S C F}\right)$ for a non-focal company in a nonOECD domicile is set to 35 days (80 days - 45 days). This is mainly due to the fact that in an ARP program, buyers are able to negotiate the payment term with the FIs individually and are potentially striving for longer payment terms. Furthermore, it is assumed that the FC will access the financing facilities at the earliest time possible. Hence the $D_{S O} O_{S F}$ is very short (three days). With respect to the payment terms without a SCF solution, it should be noted that an initial difference between the DSO of the supplier and the DPO of the buyers exists. One can argue that this is due to administrative delays or, more importantly, a general observation that nonfocal buyers have on average longer payment terms (Hofmann and Belin, 2011, p. 66). Because the goal of the model is to quantify not only the net benefit of the complete supply chain but also the net benefit to its individual members, one has to account for these initial differences.

Currently, no public information is available on platform transaction fees levied by a SCF provider or a FI. Credit Suisse (2012) notes that payments to recipients located outside the European Union ${ }^{10}$ are subject to a fee of up to $\$ 10$. The services offered by means of a platform are more extensive than an ordinary payment, and therefore transaction costs are likely higher (\$20/s are assumed) both for the supplier and buyers. The FI incurs maintenance and license fees dependent of the number of transactions. This value is set to $\$ 40 / \mathrm{s}$ (to be accounted internally or to be paid to an external platform provider). Dong (2007, p. 40) estimates the average

\footnotetext{
${ }^{10}$ Payments that are not in conformity with the ordinary SEPA payment standard.
} 
cost of securitizing a bank asset to account for approximately $1 \%$ of the asset value and also notes that the volatility of these costs is very high depending on the underlying asset quality. Therefore, the securitization parameter $\left(z_{F I}\right)$ is set to $0.3(0.3 \cdot 3 \% \approx 1 \%)$ and varies accordingly depending on the interest rate level as well as the associated risk $\left(\beta_{i}\right)$.

We assume an equal investment of $\$ 30,000$ that needs to be accounted for both the buyer and supplier. Since the ARP program is a supplier-centric SCF solution, the initial investment for the supplier (FC) should be higher $(\$ 50,000)$ and lower for the buyer $(\$ 20,000)$. This can be justified due to the fact that the supplier needs an IT infrastructure that can handle a transaction volume of up to 100 participants, while a single buyer might need a less sophisticated system, since the processed payment volume is accordingly lower. For the FI, which certainly has the highest investment needs, no public information is available ( $\$ 5$ million are assumed in the model). We expect that a non-OECD buyer may source from up to eight different suppliers for which the same platform could be used $\left(\theta_{B}=13 \%\right)$. Similarly, the FI offers the SCF solutions to a large number of customers and could split the required investment over 100 different SCF initiatives $\left(\theta_{F I}=1 \%\right)$. Furthermore, the set-up costs $\left(\kappa_{i}\right)$ are estimated to be high on purpose to demonstrate the nonlinearity of the model. Finally, the values of all remaining parameters $\left(\alpha_{i}, \omega_{i}, \gamma_{S}\right)$ not substantiated in this section, correspond to the approximations applied in the model calculations of Hofmann and Belin (2011).

Combining the findings of the previous chapters on the FSC level, the base scenario serves as a yardstick for this analysis. Our analysis mainly investigates with the number of participants required in the ARP program to lead to a favorable situation. The minimum average invoice amount is also discussed and compared for the different SCAs. Additionally, it is shown how the benefit to the FSC is to be shared among the different actors.

\subsection{FSC analysis}

First, the net benefits of the individual SCAs are compared and set in context to the net benefit to the FSC (Figure 3). 
Figure 3: Net benefit to FSC for different numbers of buyers where $A R=10 ’ 000$ and $s=50$

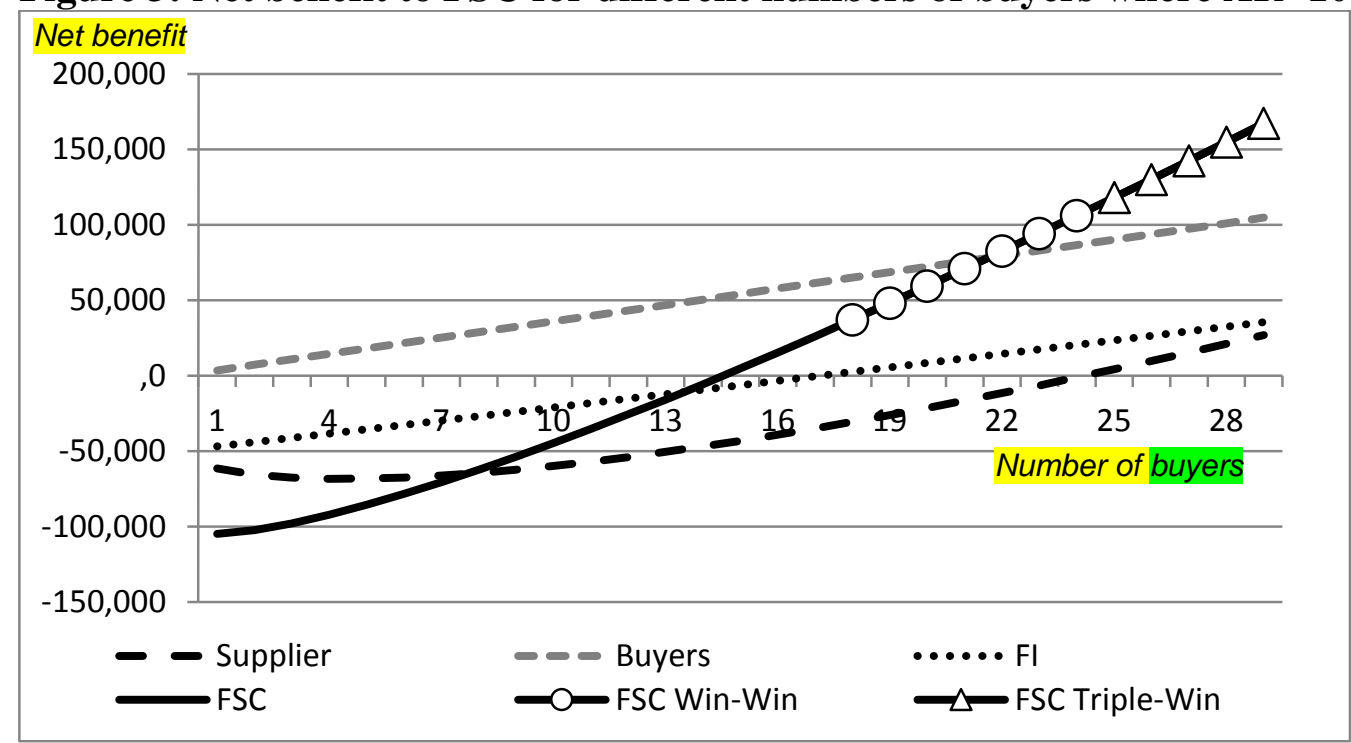

In the base scenario, to make the ARP program profitable on the FSC level $\left(\pi_{S}+\sum_{i=n} \pi_{i}+\pi_{F I} \geq 0\right)$, it is required that more than 15 buyers $(n \geq 15)$ join the program. This however does not yet imply that all actors derive a profit. The supplier is still losing money when $n \approx 15$ and is therefore partly subsidizing the net benefits to the other actors (e.g., the buyers) and also to the FI to a lesser extent, since it will break even with a lower number of participants than the supplier. Once the supplier is able to secure the minimum number of buyers needed to break even $(n \approx 25)$, one can state that all actors in the FSC derive a profit from the ARP program (triple win). With less than 25 buyers in the ARP program, there might also be a "simpler" win-win situation. As soon as the FI breaks even $(n \approx 16)$, both the FI and the buyers derive a positive net benefit in the SCF solution. However, one must keep in mind that the supplier, as the SCF initiator, is not interested in the WWS between these two parties remaining for a long time span. The supplier's goal is to design the ARP program such that the supplier also becomes a winner (derives a net benefit). In case the supplier realizes that it cannot motivate enough buyers to join the program, it might well abandon the SCF initiative. ${ }^{11}$ However, in the normal process of setting up the ARP program and with a positive outlook that enough buyers will join the SCF solution, the WWS can be seen as an intermediate step towards the TWS. As one can see later, the supplier's position (its share of FSC net benefit) will improve when additional non-focal companies join the program.

\footnotetext{
${ }^{11}$ If the supplier chooses to abandon the ARP program, the WWS between the buyers and the FI also vanishes.
} 
Even though the ARP program may lead to a net benefit on the FSC level, one cannot infer that this leads necessarily to a favorable situation (triple-win) for all actors. We therefore summarize the findings with the first proposition:

Proposition 1: A positive net benefit to the FSC $\left(\pi_{F S C}>0\right)$ does not imply a positive net benefit to all actors of the ARP program. If the supplier can motivate the required number of buyers $(n *)$ to break even, all parties are in a favorable position $\left(\pi_{S}=\pi_{B}=\pi_{F I}>0\right)$. Therefore, a triple-win situation only occurs when the supplier breaks even, or accordingly, $\pi_{S} \geq 0$, which implies that $R_{S} \geq C_{S}$.

\subsection{Allocation analysis of FSC benefit}

Having introduced the findings of the base scenario on the FSC level, it is also of interest how the benefits derived from the ARP program are to be shared among the different SCAs. It has been previously shown that all buyers are in a favorable situation in the base scenario ( $n=60)$ and that the supplier needs a considerable number of participants to make the program profitable.

Figure 4: Share of FSC net benefit for different number of buyers where $A R=10,000$ and $\mathbf{s}=\mathbf{5 0}$

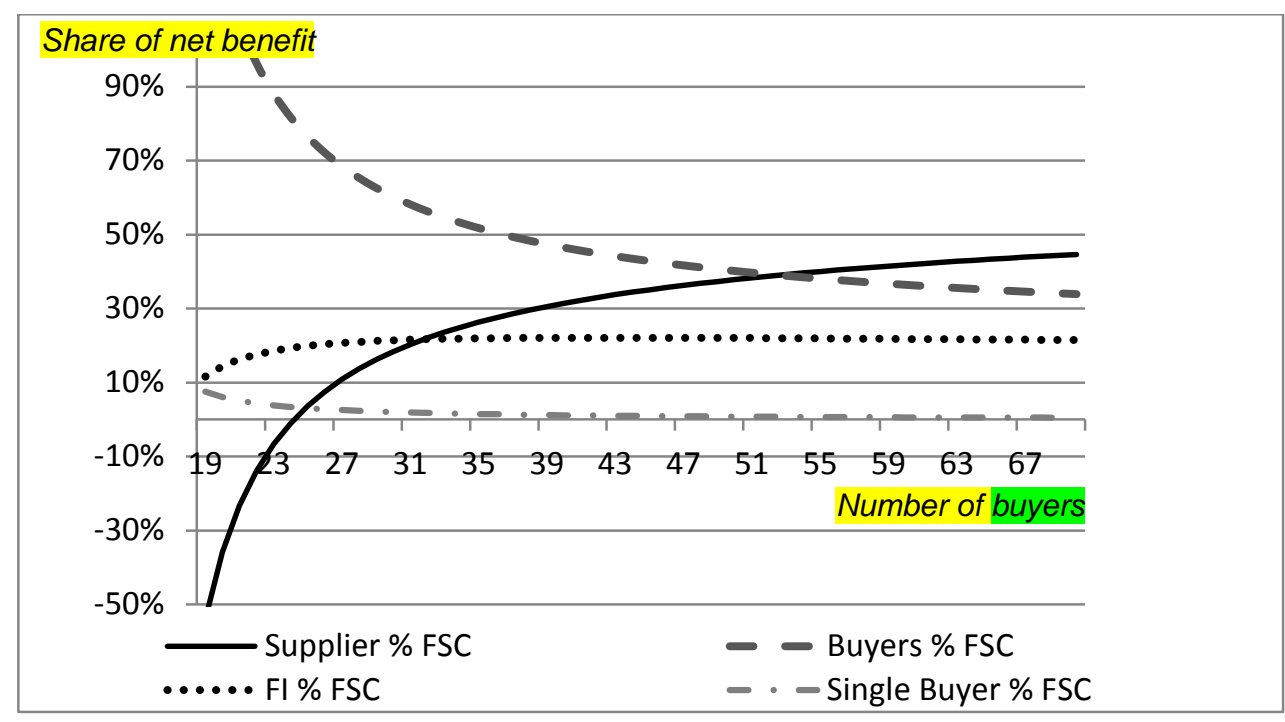

Figure 4 shows that with an increasing number of buyers participating in the SCF initiative, the supplier tends to take the largest share of the FSC benefit. When aggregated, the buyers take a considerable share of the FSC benefit, especially with a low number of participants in the program. However, looking at the individual share of a single buyer, this statement needs to be put in perspective: Since the net benefit of a single buyer is very low, its share on the FSC level 
is also low. The FI, as the third main actor in the ARP program, is also able to recover from the initial losses and can secure a stable share of the benefit. In this situation, a TWS appears to take effect as soon as the supplier takes a positive share of the FSC benefit.

When deriving the net benefits of the individual actors, reference was made to the break even payment balance for a fixed number of buyers $(n=60)$ and transactions $(s=50)$. Table 6 presents the corresponding results (for the respective SCAs and the FSC), such as $\pi_{F S C}=0$.

Table 6: Break even payment balance for all actors where $s=50$ and $n=60$

\begin{tabular}{|c|c|c|c|c|}
\hline & Supplier's & Buyer 's & FI's & FSC's \\
& $A R_{S}{ }^{*}$ & $A P_{B}{ }^{*}$ & $\boldsymbol{A P B}_{F}{ }^{*}$ & $\boldsymbol{A P B}_{F S C}{ }^{*}$ \\
\hline $\begin{array}{c}\text { Payment } \\
\text { balance }\end{array}$ & $\approx 5,723$ & $\approx 5,565$ & $\approx 5,074$ & $\approx 5,536$ \\
\hline
\end{tabular}

To make the ARP program profitable given the trade characteristics of the base scenario, the involved parties are willing to participate in the ARP program if the payment balance exceeds the respective amount given a set of payments (here $s=50$ ). For example, only when a supplier recruits more buyers to the program or when the buyer increases its transaction frequency, a lower payment balance may be accepted in the short term. In this case, one can note the following: $A R_{S}^{*}>A P_{B}{ }^{*}>A P B_{F S C} *>A P B_{F I}{ }^{*}$, which leads us to our second proposition:

Proposition 2: If the payment balance exceeds $A P B_{F S C} *$ but is lower than the one required by the buyer $\left(A P_{B}^{*} \geq A P B \geq A P B_{F S C}{ }^{*}\right)$, the FI is the sole actor in the FSC that derives a positive net benefit (it holds that $A P B_{F S C}{ }^{*}>A P B_{F I} *$ ). For the remaining actors (focal supplier and its buyers), it is not feasible to trade through the ARP program. Consequently, the opposite is true when the payment balance increases and is above $A R_{S}^{*}$, and all actors derive a positive result from the SCF initiative. ${ }^{12}$

The following subsection presents different scenarios for the ARP program and shows whether the two propositions hold for transaction volumes other than in the base scenario.

\subsection{Scenario analysis}

The base scenario has already shed light on the benefits of the ARP program for the involved actors. By means of the same model, this part aims to illustrate how different trade characteristics (e.g., higher payment balance combined with a lower transaction frequency) may

\footnotetext{
12 The win-win situation between the buyer and the FI discussed previously already occurs at a payment balance of $A P_{B}^{*} \leq A P B \leq A R_{S}^{*}$.
} 
influence the net benefit of the individual SCAs on the one hand and the result on the aggregated FSC level on the other hand. Again, the average payment balance $\left(A P B_{F S C}{ }^{*}\right)$ and the transaction frequency (s) are fixed, and the analysis focuses on how the net benefit to the SCAs changes with different numbers of participants in the model (Table 7).

Table 7: Scenarios for the ARP program

\begin{tabular}{|c|c|c|c|c|}
\hline & $\boldsymbol{A P B}_{\mathrm{FSC}} \boldsymbol{*}^{*}$ & $\boldsymbol{S}$ & $\begin{array}{c}\text { Export value for the FC } \\
\text { where } n=n_{\max }\end{array}$ & Comment \\
\hline Base scenario & 10,000 & 50 & $\$ 50 \mathrm{~m}$ & Base scenario \\
\hline Scenario 1 & $\begin{array}{c}5,000 \\
(-50 \%)\end{array}$ & 50 & $\$ 25 \mathrm{~m}$ & $\begin{array}{c}\text { Lower payment balance } \\
\text { combined with average } \\
\text { transaction frequency }\end{array}$ \\
\hline Scenario 2 & $\begin{array}{c}5,000 \\
(-50 \%)\end{array}$ & $\begin{array}{c}40 \\
(-20 \%)\end{array}$ & $\begin{array}{c}\text { Lower payment balance } \\
\text { combined with lower trans- } \\
\text { action frequency }\end{array}$ \\
\hline Scenario 3 & $35,000(+250 \%)$ & $\begin{array}{c}30 \\
(-40 \%)\end{array}$ & $\begin{array}{c}\text { Higher payment balance } \\
\text { combined with lower trans- } \\
\text { action frequency }\end{array}$ \\
\hline
\end{tabular}

Scenario 1 assumes that the average payment balance decreases while the transaction frequency remains the same as in the base scenario. It has been previously indicated that in the case that the average invoice value is substantially lowered, the actors would likely incur a loss. In contrast to the base scenario, however, this scenario makes use of the fact that the platform capacity allows more buyers. Consequently, it can be shown that the lower payment balance of $\$ 5,000$ might also lead to a feasible situation for some of the actors involved. Not surprisingly, here the supplier and the FI need more buyers to participate in the program to break even. The participating buyers ${ }^{13}$ will lose money in this scenario, even though the loss to a single buyer is rather low $\left(\pi_{B} \approx-\$ 450\right)$. The fact that the buyers derive a negative net benefit preempts the possibility of a pure triple-win situation, as observed in the base scenario from the beginning.

Both for the supplier and the FI, the convexity of their net benefit function becomes more pronounced when lowering the average invoice amount, which is mainly due to the buyer-specific set-up costs that are assumed to remain stable, even though the transaction volume decreases. Consequently, the marginal benefit of one buyer joining the ARP program for both the supplier and the FI is smaller than in the base scenario. This essentially means that for the complete FSC, one additional participant adds less value than in the base scenario. ${ }^{14}$

\footnotetext{
${ }^{13}$ If the buyer does not receive additional intangible benefits or is not forced for any other reason to participate in the AR/P program, it would clearly opt out from the SCF solution.

${ }^{14} \pi_{F S C}^{1}(n)<\pi_{F S C}^{B}{ }^{\prime}(n)$.
} 
Scenario 2 shows that WWSs are not always inherent in SCF solutions. With an average invoice value of $\$ 5,000$ paired with a lower transaction frequency $(s=40)$ than in the base scenario, the ARP program could be rather termed a "triple-lose situation.” None of the SCA would derive a positive net benefit from the SCF solution where $n \leq 100$. Therefore, a discussion on possible win-win- or even triple-win situations is unnecessary. With more buyers joining the program, the FSC benefit initially decreases even on a larger scale than in the previously discussed cases. This is due on the one hand to the fact that for the supplier and the FI, the marginal benefit of one buyer joining the program further declines (in comparison to the base scenario and scenario 1) and turns positive at higher values of $n$. On the other hand, a substantial loss of buyers adds up faster and therefore impacts the FSC result to a larger extent than in scenario 1. One could argue that the marginal benefit to the FSC of one buyer joining the platform is constantly diminished by the loss of the buyer, since in this scenario, it always holds that $\pi_{B}<0$ for every buyer in the program. Therefore, both a decrease in the average invoice value and the transaction frequency changes the picture substantially compared to the base scenario.

Scenario 3 finally introduces a case in which the average payment balance is considerably higher $(\$ 35,000)$. However, fewer transactions occur $(s=30)$ between the involved parties. Still, the potential total export value for the FC as well as the transaction volume per buyer (\$105 m / \$1.05 m) is more than doubled compared to the base scenario. The linearity of the FSC net benefit in terms of the number of buyers in the program occurs for different reasons. First of all, the FSC benefit receives more impact from the linear buyer function. Secondly, the shape of the net benefit from both the FI and the supplier (FC) tends to be less convex. This is due to the fact that all the previously introduced formulas are linear in the average payment balance. Nevertheless, one can observe some distinguishing features compared to the earlier introduced cases. For the FI and the FC, both break even with fewer participants in the ARP program. Furthermore, it can be stated that for both of them that the net benefit increases from the first buyer joining the SCF solution. However, this does not imply a positive result for these two actors if the number of participants is very low; it shows that the rather high set-up costs play a less major role when the transaction volume per single buyer increases considerably. In essence, the findings in scenario 3 do not considerably deviate from the base scenario. It shows that SCF solutions (here an ARP program) are most beneficial when the export volume is high. In practice, one has to note that the potential number of FCs that can export goods for an average value of $\$ 1.05$ million to 100 non-OECD buyers might be limited to a small range of large multinational companies. 
Summary: Whether the respective financial flows will be handled through the SCF platform naturally depends on the involved actors' willingness to participate in the ARP program. Table 8 summarizes the decisions of the involved parties based purely on financial terms, assuming the platform capacity with regards to the numbers of buyers is maximized $(n=100)$ in each scenario. Since the model did not specify a minimum required return (net benefit), it is assumed that each SCA will participate in the SCF initiative if $\pi_{i} \geq 0$ and opt out from the program if $\pi_{i}<0 .{ }^{15}$ Furthermore, the results of the required number of buyers (n*) to break even for the focal supplier (FC) is presented. As suggested by Proposition 1, TWSs occur when the supplier breaks even. Scenario 3 is consistent with this statement. For scenarios 1 and 2, this statement cannot be true, since at least one of the SCAs is not willing to participate in strict terms.

Table 8: Summary results scenario analysis

\begin{tabular}{|c|c|c|c|c|c|c|}
\hline & \multicolumn{2}{|c|}{ Supplier (FC) } & \multicolumn{2}{c|}{ FI } & Buyers & FSC \\
\cline { 2 - 7 } & \multicolumn{2}{|c|}{ Decision / $n^{*}$} & \multicolumn{2}{|c|}{ Decision / $n^{*}$} & Decision & $n^{*}$ \\
\hline $\begin{array}{c}\text { Base scenario } \\
\mathrm{APB}=10,000 / \mathrm{s}=50\end{array}$ & Participate & $\begin{array}{c}25 \\
\text { (TWS) }\end{array}$ & Participate & 18 & Participate & 15 \\
\hline $\begin{array}{c}\text { Scenario 1 } \\
\mathrm{APB}=5,000 / \mathrm{s}=50\end{array}$ & Participate & $\begin{array}{c}77 \\
\text { (WWS) }\end{array}$ & Participate & 62 & $\begin{array}{c}\text { Do not } \\
\text { participate }\end{array}$ & 82 \\
\hline $\begin{array}{c}\text { Scenario 2 } \\
\mathrm{APB}=5,000 / \mathrm{s}=40\end{array}$ & $\begin{array}{c}\text { Do not par- } \\
\text { ticipate }\end{array}$ & 115 & $\begin{array}{c}\text { Do not par- } \\
\text { ticipate }\end{array}$ & 107 & $\begin{array}{c}\text { Do not } \\
\text { participate }\end{array}$ & 173 \\
\hline $\begin{array}{c}\text { Scenario 3 } \\
\mathrm{APB}=35,000 / \mathrm{s}=30\end{array}$ & Participate & $\begin{array}{c}9 \\
\text { (TWS) }\end{array}$ & Participate & 5 & Participate & 5 \\
\hline
\end{tabular}

Finally, let us consider the allocation of the FSC benefits for the different scenarios and assume for each scenario that the platform capacity is at its maximum $(n=100)$. As illustrated earlier, the supplier net benefit steadily grows with more participants in the program, and the aggregated buyers' share decreases. It must be noted that Figure 5 does not include the results from scenario 2 since the initiative is not profitable for any SCA. Furthermore, the share of a single buyer is negligible and therefore not incorporated in the graph.

\footnotetext{
${ }^{15}$ Win-win condition according to Giannoccaro and Pontrandolfo (2004, p. 132).

${ }^{16}$ Note: For scenario 2, the values of $n *$ hold for the parameter values as defined in the base scenario. Since the maximum capacity for the platform solution has been set to 100 participants, the corresponding results should be treated with caution.
} 
Figure 5: Share of FSC net benefits where $n=100\left(n_{\max }\right)$

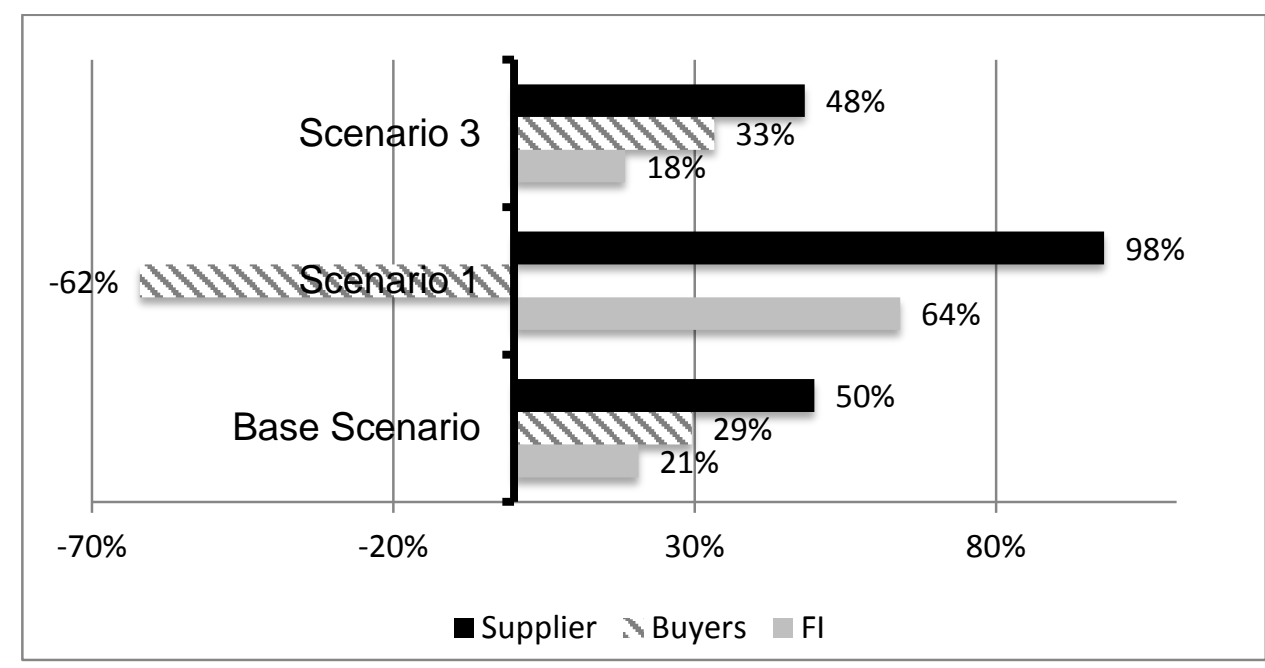

The most favorable scenarios in which a TWS can be derived (base scenario and scenario 1) show that approximately half of the FSC net benefit will be captured by the initiating firm, the FC (supplier). As the transaction volume increases (scenario 3), the buyers' share may increase (up to 33\%) but leaves the overall picture unchanged. The FI secures approximately a fifth of the total FSC net benefit in both cases. Even though the findings show that in scenario 1 the buyers would not participate in the ARP program, the hypothetical allocation of the benefits in the case that they would do so is also included. A win-win situation is not certain.

\subsection{Model robustness}

Having introduced different scenario calculations, the model examination is now concluded with a sensitivity analysis by adjusting selected parameter values. Table 9 includes two parameters each for every SCA. 
Table 9: Net Benefit to the FSC where $A P B=10,000, s=50$, and $n=60$

\begin{tabular}{|c|c|c|c|c|c|c|c|}
\hline \multicolumn{2}{|c|}{ Supplier } & \multicolumn{2}{|c|}{ Buyer } & \multicolumn{2}{|c|}{ FI } & \multicolumn{2}{|c|}{ Net benefit } \\
\hline$D S O_{S C F}$ & WACC $_{S}$ & $D P O_{S C F}$ & $\beta_{B}$ & $c_{F I}$ & $\kappa_{F I}$ & $\pi_{S C A}$ & $\pi_{F S C}$ \\
\hline $3 d$ & $8 \%$ & $80 \mathrm{~d}$ & 1.7 & $1 \%$ & 8,000 & $\begin{array}{c}\pi_{\mathrm{S}}=248^{\prime} 940 \\
\pi_{B}=3^{\prime} 610 \\
\pi_{H}=129^{\prime} 674\end{array}$ & 595,233 \\
\hline $\begin{array}{c}20 \mathrm{~d} \\
(+800 \%)\end{array}$ & $8 \%$ & $80 \mathrm{~d}$ & 1.7 & $1 \%$ & 8,000 & $\begin{array}{l}215,597 \\
\mathbf{( - 1 3 \% )}\end{array}$ & $\begin{array}{c}545,926 \\
\mathbf{( - 8 \% )}\end{array}$ \\
\hline $3 d$ & $\begin{array}{c}10 \% \\
(+25 \%)\end{array}$ & $80 \mathrm{~d}$ & 1.7 & $1 \%$ & 8,000 & $\begin{array}{l}326,041 \\
(+30 \%)\end{array}$ & $\begin{array}{l}672,334 \\
(+13 \%)\end{array}$ \\
\hline $3 d$ & $8 \%$ & $\begin{array}{c}70 \mathrm{~d} \\
(-12 \%) \\
\end{array}$ & 1.7 & $1 \%$ & 8,000 & $\begin{array}{c}1,286 \\
\mathbf{( - 6 4 \% )} \\
\end{array}$ & $\begin{array}{l}430,809 \\
(-\mathbf{1 3 \%}) \\
\end{array}$ \\
\hline $3 d$ & $8 \%$ & $80 \mathrm{~d}$ & $\begin{array}{c}1.3 \\
(-24 \%)\end{array}$ & $1 \%$ & 8,000 & $\begin{array}{l}3,338 \\
\mathbf{( - 8 \% )} \\
\end{array}$ & $\begin{array}{l}494,957 \\
(-28 \%)\end{array}$ \\
\hline $3 d$ & $8 \%$ & $80 \mathrm{~d}$ & 1.7 & $\begin{array}{c}1.2 \% \\
(+20 \%)\end{array}$ & 8,000 & $\begin{array}{l}145,000 \\
(+\mathbf{1 2 \%})\end{array}$ & $\begin{array}{c}610,559 \\
(+3 \%)\end{array}$ \\
\hline $3 \mathrm{~d}$ & $8 \%$ & $80 \mathrm{~d}$ & 1.7 & $1 \%$ & $\begin{array}{c}6,000 \\
(-25 \%)\end{array}$ & $\begin{array}{l}160,326 \\
(+25 \%)\end{array}$ & $\begin{array}{c}625,885 \\
(+5 \%)\end{array}$ \\
\hline
\end{tabular}

The first two parameters assessed refer to the payment term and the cost of capital of the supplier. As expected, one can observe an inverse relationship between the payment term and the supplier's net benefit. As the cost of capital increases, the benefit from unlocking working capital increases considerably, and therefore it is even more advantageous to participate in an ARP program for the supplier. For a single buyer, one can observe that the payment terms will have a significant impact on the decision whether to participate in a SCF solution. However, for the FSC, the impact is limited because the payment terms of the buyers do not affect the benefit of the supplier and benefit the FI only to a limited extent. If the riskiness of the non-OECD buyer decreases (as can be observed in the table above in terms of a smaller $\boldsymbol{\beta}_{\boldsymbol{B}}$ ), the net benefit of the buyer will change moderately, since the perceived benefit from access funding at OECD terms is reduced. Notably, the benefit of the FSC in this case will shrink substantially, mainly due to the fact that the supplier's gain declines (higher $\boldsymbol{\beta}_{\boldsymbol{B}}$ implies a higher risk benefit for the supplier). Assessing the change in the cross-selling income of the FI $\left(\boldsymbol{c}_{\boldsymbol{F I}}\right)$, it can be observed that the adjustment only has a limited impact on the results of the FSC, since this parameter is solely FI centric. The same holds true for a reduction of the set-up costs $\left(\kappa_{F I}\right)$ incurred by the FI, which ultimately translates to an increase of the net benefit of a similar magnitude.

\section{Discussion}

\subsection{Actors in the ARP program}

The analyses show that for every SCA, the SCF solution becomes more favorable when transaction volumes and frequencies grow. As these are increasing, the strategic importance of the relationship between the involved parties can also be assumed to be positively affected. 
Existing literature from the general SCM perspective (e.g., Maloni and Benton, 1997) but also from the SCF angle (e.g., Seifert, 2010) supports this view, and researchers have stated that the nature of the relationships between the focal supplier and the buyers need to be of strategic importance to derive a WWS. In the context of this paper, this conceptual link is also true for the relationship that the FI has with both the supplier and the buyers. As transaction volumes decline noticeably, FIs are less interested in acting as a liaison between suppliers and buyers.

From the viewpoint of the initiating FC, the success of the ARP program depends most probably on the extent of its market position and therefore the ability to convince its buyers to take part in such an advanced financing program. The question then arises whether a strong FC can put pressure on its buyers to adopt such a SCF solution. The FC will likely take the largest share of the (tangible) benefit if the ARP program is successfully implemented, and trading will take place over an extended time period. However, the FC is also prone to the largest losses when the initiative fails (e.g., from not enough buyers in the program) and is therefore unlikely to bear the initial effort if there is no certainty (e.g., contractual agreements in place) before taking up the initiative. The FC-assuming that its operations and financial health are soundmay have other financing sources that can be tapped to finance its export transactions.

Furthermore, our analyses support the findings of Hofmann and Belin (2011), who stated that the potential benefits for the exporting FCs substantially outweigh the buyers' share. For non-focal companies that participate in the ARP program, it has been shown that the tangible benefits are limited (both on an aggregated and single-company level). Nevertheless, our findings confirm that the interest rate arbitrage, which was also postulated by Seifert and Seifert (2011), is indeed the source of a potential benefit on the buyers' side. However, one might question whether this gap in the OECD and non-OECD context remains as big in the long term as supposed in the model. Whether buyers can compensate for the rather small monetary gains with further (intangible) benefits (e.g., enhancement of reputation), which are harder to measure in monetary terms, remains an open question. Therefore, it might be a possible scenario that as a result of the closer financial collaboration, the buyers could profit from enhanced trust in the supplier-buyer relationship, which would eventually lead them to source goods at more favorable prices.

Finally, it has also been shown that SCF initiatives can indeed yield profits for the FI. This is of course not surprising; otherwise, these offerings would not exist in practice. Still, the general limitations with regards to transaction volumes apply, and a bank would most likely only engage in an ARP program if it already has a close relationship with the FC. Since the initial receivables purchasing agreement is conducted between the FC and the FI, the bank would 
clearly have to define a minimum transaction volume with its main partner. Leaving this aside, the FI's gains are similar to those from other “ordinary” loan facilities that are highly dependent on the funding margin, which seems reasonable.

\subsection{Towards triple win in supply chain finance}

Though the objective of this paper focuses on the triple-win notion, the win-win case on the FSC level has also been discussed throughout the paper and therefore requires some reflection. From the viewpoint of the network, a fundamental goal is to make the whole supply chain more efficient, to bond less capital and to reduce risks to a max. The perspective in this paper however differs from conventional SCF literature that often focuses on collaborative agreements between two close network partners. Therefore, it is still arguable that the FI can or should be treated as a pure network or SC member.

As could be observed in the different scenarios, a positive net benefit for the FSC does not necessarily imply that all SCAs are better off. Surprisingly, the pure WWS between the FC (supplier) and the buyer does not appear. Of course, once a TWS is prevalent, one can also argue that a WWS between these two SCAs exists. However, given the structure of our analysis, one can infer another interesting case. Prior to the occurrence of a TWS, the FI finds itself often in a WWS together with the buyers (as observed in the base scenario and scenario 3, where transaction volumes were highest). At this stage, the supplier accepts a loss for the sake of the overall SC performance. The SC literature on the win-win notion (e.g., Lanier et al., 2010) favors such supplier behavior in the case that the network benefit is positive. One has to bear in mind that at this state (with a relatively small number of buyers in the ARP program), the supplier "subsidy" can result in a situation in which the FI is the biggest winner. Therefore, this

case is not completely comparable to the situation described by Chandra and Kumar (2000), who supported such supplier behavior only in the case in which its immediate partners (buyers) profit from increased collaboration. However, since transaction volumes in the mentioned scenarios are quite high, the supplier might be ready to accept a loss at this stage.

Another WWS could be observed in scenario 1, with the supplier and the FI as the two winners. This case occurs when a large number of buyers join the ARP program and the transaction volumes are considered moderate. Though this case could be more realistic to sustain over a longer time period, there is one important precondition. If the incentive for the buyers to participate in the ARP program only rests on monetary terms, then the FC would probably have to sacrifice a share of its own profits and take over part of the costs that arise on the buyer's side (e.g., with regards to the fixed IT costs). A TWS can only be achieved if this happens. To 
close the discussion, even if a TWS can be achieved, a fair distribution of the resulting benefits, as advocated by Giannoccaro and Pontrandolfo (2004), is hardly possible. The share of the FI's benefit can be seen as a given. It is then up to the suppliers and buyers reallocate potential benefits arising from a collaborative payment scheme, as for example described by Hofmann 2006.

\section{Conclusion}

\subsection{Main contributions}

A specific goal of our study was to address the question of whether SCF solutions can indeed lead to a mutually favorable value proposition for suppliers, buyers, and FIs. In summary, the main findings out of this analysis are the following:

- The model analysis has shown that SCF initiatives have the potential to create tripartite value for suppliers, buyers and FIs (triple win situations). A net benefit to the FSC however, does not simultaneously imply a net benefit to all involved parties. It mainly depends on the net benefit of the focal company (vendor), whether such a situation can be achieved. Hence, for the FC to initiate an accounts receivable-oriented SCF initiative, a large number of buyers as well as a high transaction frequency are essential.

- The net benefit of the FSC is shared unequally among the involved parties with the result that the FC emerges as the biggest "winner" after a successful implementation of an accounts receivable platform.

- All actors in the SCF initiative are highly sensitive to the average payment balance ( $A P B^{*}$ )and hence to the total (export) volume handled via a SCF initiative. Depending on the terms (frequency and number of participants) the sensitivity differs. However, in general one can note that due to relatively high set-up expenses, FIs and supplying FCs are most dependent on high transaction volumes for a successful introduction of an accounts receivable platform.

The academic contributions of this paper are manifold. For academics interested in the more broad SCM perspective, our results support existing literature on WWS outlining that the financial benefit of a single actor is only a side effect (Lanier et al., 2010) and should be rather assessed based on the overall SC performance. On the contrary, we oppose the view by Giannoccaro and Pontrandolfo (2004) and come to the conclusion that a fair allocation (from a financial perspective) is hard to achieve. In addition, our analysis shows that the implementation of a mutually beneficial SCF initiative requires that the involved actors have in-depth knowledge of their counterparts. Therefore, similar to Vlachos (2004), Cooper and Ellram 
(1993) and Towill (1997), we support the notion that close collaboration (cooperative behavior) over a long time horizon between the SCAs is a prerequisite for a WWS.

To conclude, we made the following contributions:

- Our study introduces a concrete accounts receivable financing solution to the supply chain finance literature. Fundamental works like Hofmann (2005), Pfohl and Gomm (2009), Hofmann and Belin (2011) or Wuttke et al. (2013) are complemented by an export financing model analysis.

- A further contribution relates to SCM literature. According to Fisman and Love (2003), Camerinelli (2009b) and-more precisely_-Silvestro and Lustrato (2014), we established financial service providers (especially banks and SCF platforms) as relevant parties in the supply chain. We expect financial institutions to be an indispensable part of SCM, like logistics service providers have been since the 1990’s (e.g. Lieb and Randall, 1996; Berglund et al., 1999) or ICT providers since the 2000’s (e.g. Christiaanse and Kumar, 2000; Gunasekaran and Ngai, 2004).

- Another contribution refers to the advancement of factoring approaches in the finance literature stream. Insights from Soufani (2002), Palia and Sopranzetti (2004) or Klapper (2006) are supplemented with "supply chain thinking”.

- Finally, our study contributes towards the establishment of win-win situations in the general management literature (e.g. Elkington, 1994; Bertrand, 1986; Van der Veen and Venugopal, 2005). Even though this contribution might be somewhat exaggerated, we introduced a specific case for triple win in case of SCF.

\subsection{Limitations}

The first limitation pertains to the general FSC structure for the export-oriented SCF solution. While it is assumed in the model that one FI can act both as a funder and platform provider and therefore coordinate the financial flows in the ARP program alone, this situation is unlikely to happen in practice. It would require that the FI has a close relationship with numerous participating buyers in the non-OECD countries. The feasibility of setting up these relationships could also be questionable from a regulatory viewpoint. Therefore, an additional specialized service provider is likely to take a key role in the ARP program.

Secondly, the model presented is in essence designed as a one-period model. However, the set-up process for SCF solutions requires a long time period that could last up to two years. The model does not incorporate this fact. The actors will also base their decisions to participate in a SCF solution based on the (fixed) costs that occur once the ARP program is ready to be implemented. Accordingly, the set-up costs that were accounted for in the model should only occur 
in the first period (year) in practice. Also related to the time horizon is the general question of how the model parameters (e.g., funding fees and risk for the FI) change as the SC relationships mature and the SCF solution is applied in a multi-period setting. The FI may or may not lock in the actors once the ARP program is well established and could therefore potentially charge higher fees.

Furthermore, to investigate whether the FI is indeed a third winner in the context of SCF, it would likely require not only measuring the FI's net benefit of engaging in such a collaborative scheme but also defining a certain minimum (risk-adjusted) return on assets or equity. Unlike the suppliers or buyers, for which the gains from the SCF solution are a form of "additional benefit," the provision of ARP loan facilities directly impacts the FI's core business (financial intermediation). Therefore, another perspective from which to measure the effective gain would be desirable. In addition, by establishing SCF solutions in an OECD and non-OECD trade relationship, the net benefit for the FI derived in the described model partially comes at the expense of other FIs that conduct business with the non-OECD SCAs (buyers in this case) and that would accordingly sustain losses on their interest income.

A final limitation concerns the narrow overall trade potential for non-OECD-directed exports, which clearly restricts the applicability of the discussed financing mechanism.

\subsection{Future research}

To date, little research has addressed triple-win situations. Our paper offers opportunities for more research in this pioneering field and should be seen as a first attempt to shed light on the interrelationships between the actors in the supply chain.

This paper has reviewed and built on literature focusing on the win-win notion especially from a SCF perspective. An attempt to model and derive the net benefits of a special form of network finance (ARP program) can be seen as the chief theoretical contribution of this paper. While using the cost benefit analysis of Hofmann and Belin (2011) as a baseline, the extension of their model to incorporate FIs into the SCF setting can be seen as another important input for the academic discussion. With the scenario analyses conducted to test the applicability of the model, it has been observed that the net benefits tend to grow linearly with increasing transaction volumes handled through the SCF platform mechanism. Future research should critically question this correlation.

While this paper focused on a single-bank platform, it neglected the fact that companies in the international trade context do have relationships with multiple banks and may operate in 
various "financial nets". To what extent these more complex, multi-bank interrelationships might affect the triple-win notion is left to future research.

Finally, limited data on SCF transactions and FI solutions exist that are grounded in academic work. Therefore, to better investigate the tripartite perspective as attempted in this paper, more needs to be known about this actor in the FSC. Also, with regards to enhanced capital allocation - which was initially stated to be one of the driving factors for banks to engage in SCF initiatives—vast potential for empirical research remains.

\section{References}

Baños-Caballero, S., García-Teruel, P. J., Martínez-Solano, P. (2010). Working Capital Management in SMEs. Accounting \& Finance 50(3), 511-527

Berglund, M., Van Laarhoven, P., Sharman, G., Wandel, S. (1999). Third-Party Logistics: Is There a Future?. The International Journal of Logistics Management 10(1), 59-70

Bertrand, K. (1986). Crafting Win-Win Situations in Buyer-Supplier Relationships. Business Marketing 71(6), 42-50

Boot, A. (2000). Relationship Banking: What Do We Know? Journal of Financial Intermediation 9(1), 7-25

Camerinelli, E. (2009a). Measuring the Value of the Supply Chain. Surrey: Gower Publishing Ltd.

Camerinelli, E. (2009b). Supply Chain Finance. Journal of Payments Strategy and Systems 3(2), 114-128

Chandra, C., Kumar, S. (2000). Supply Chain Management in Theory and Practice: A Passing Fad or a Fundamental Change? Industrial Management \& Data Systems 100(3), 100-114

Christiaanse, E., Kumar, K. (2000). ICT-enabled Coordination of Dynamic Supply Webs. International Journal of Physical Distribution \& Logistics Management 30(3/4), 268-285

Chua, W., Mahama, H. (2007). The Effect of Networking Ties on Accounting Controls in a Supply Alliance, Contemporary Accounting Research 24(1), 47-86

Cooper, M., Ellram, L. (1993). Characteristics of Supply Chain Management and the Implications for Purchasing and Logistics Strategy. The International Journal of Logistics Management 4(2), 13-24

Copeland, T., Weston, J., Shastri, K. (2005). Financial Theory and Corporate Policy. Fourth Edition. Pearson Addison Wesley

Corbett, C., DeCroix, G. (2001). Shared Savings Contracts for Indirect Materials in Supply Chains: Channel Profits and Environmental Impacts. Management Science 47(7), 881-893 
Credit Suisse (2012). Overview of Prices and Conditions for Companies. Accessed online: https://www.credit-suisse.com/ch/unternehmen/kmugrossunternehmen/doc/konditionen_en.pdf

Deloof, M. (2003). Does Working Capital Management Affect Profitability of Belgian Firms? Journal of Business Finance \& Accounting 30 (3-4), 573-587

Dong, Y. (2007). Analysis on Cost of Securitization and Its Implication on Asset Quality Deterioration in Banks with Empirical Evidence. University of Essex, Southwestern University of China. Accessed online: http://www.ccfr.org.cn/cicf2007/download.php?paper=20070115201641.PDF

Elkington, J. (1994). Towards the Sustainable Corporation: Win-Win-Win Business Strategies for Sustainable Development. California Management Review 36(2), 90

Fairchild, A. (2005). Intelligent Matching: Integrating Efficiencies in the Financial Supply Chain. Supply Chain Management: An International Journal 10(4), 244-248

Farris II, M., Hutchinson, P. (2003). Measuring Cash-to-Cash Performance. The International Journal of Logistics Management 14(2), 83-91

Fisman, R., Love, I. (2003). Trade Credit, Financial Intermediary Development, and Industry Growth. The Journal of Finance 58(1), 353-374

Giannoccaro, I., Pontrandolfo, P. (2004). Supply Chain Coordination by Revenue Sharing Contracts. International Journal of Production Economics 89(2), 131-139

Gunasekaran, A., Ngai, E.W. (2004). Information Systems in Supply Chain Integration and Management. European Journal of Operational Research 159(2), 269-295

Gunasekaran, A., Patel, C., Tirtiroglu, E. (2001). Performance Measures and Metrics in a Supply Chain Environment. International Journal of Operations \& Production Management 21(1), 71-87

Hofmann, E. (2005). Supply Chain Finance: Some Conceptual Insights. In: Lasch, R., Janker, C. eds. Logistik Management - Innovative Logistikkonzepte (pp. 203-214), Wiesbaden Hofmann, E. (2009). Inventory Financing in Supply Chains: A Logistics Service ProviderApproach. International Journal of Physical Distribution \& Logistics Management 39(9), 716-740

Hofmann, E. 2006. Quantifying and Setting Off Network Performance. International Journal of Networking \& Virtual Organisations 3(3), 317-339.

Hofmann, E., Belin, O. (2011). Supply Chain Finance Solutions: Relevance - Propositions Market Value. Berlin Heidelberg: Springer Verlag

Hofmann, E., Kotzab, H. (2010). A Supply Chain-oriented Approach of Working Capital Management. Journal of Business Logistics 31(2), 305-330 
Klapper, L. (2006). The Role of Factoring for Financing Small and Medium Enterprises. Journal of Banking \& Finance 30(11), 3111-3130

Kouvelis, P., Zhao, W. (2012). Supply Chain Finance. In: Kouvelis, P., Dong, L., Boyabatli, O. and Li, R. eds. Handbook of Integrated Risk Management in Global Supply Chains (Ch. 10), John Wiley and Sons Inc., New Jersey

Lambert, D., Cooper, M. (2000). Issues in Supply Chain Management. Industrial Marketing Management 29(1), 65-83

Lanier Jr., D., Wempe, W., Zacharia, Z. (2010). Concentrated Supply Chain Membership and Financial Performance: Chain- and Firm-Level Perspectives. Journal of Operations Management 28(1), 1-16

Lieb, R.C., Randall, H.L. (1996). A Comparison of the Use of Third-Party Logistics sServices by Large American Manufacturers, 1991, 1994, and 1995. Journal of Business Logistics 17(1), 305

Maloni, M., Benton, W. (1997). Supply Chain Partnerships: Opportunities for Operations Research. European Journal of Operational Research 101(3), 419-429

Miller, M., Modigliani, F. (1958). The Cost of Capital, Corporation Finance and the Theory of Investment. The American Economic Review 48(3), 261-297

Palia, D., Sopranzetti, B.J. (2004). Securitizing Accounts Receivable. Review of Quantitative Finance and Accounting 22(1), 29-38

Pfohl, H.C., Gomm, M. (2009). Supply Chain Finance: Optimizing Financial Flows in Supply Chains. Logistics Research 1(3-4), 149-161

Raheman, A., Nasr, M. (2007). Working Capital Management And Profitability - Case of Pakistani Firms. International Review of Business Research Papers 3(1), 279-300

Randall, W., Farris II, M. (2009). Supply Chain Financing: Using Cash-to-Cash Variables to Strengthen the Supply Chain. International Journal of Physical Distribution and \& Logistics Management 29(8), 669-689

Seifert, D. (2010). Collaborative Working Capital Management in Supply Networks. Dissertation. École Polytechnique Fédérale de Lausanne

Seifert, D., Seifert, R. (2011). Financing the Chain. International Commerce Review 10(1), $32-44$

Silvestro, R., Lustrato, P. (2014). Integrating Financial and Physical Supply Chains: the Role of Banks in Enabling Supply Chain Integration. International Journal of Operations \& Production Management 34(3), 298-324.

Soufani, K. (2002). The Decision to Finance Account Receivables: the Factoring Option. Managerial and Decision Economics 23(1), 21-32. 
SWIFT. (2012). Trade Services Utility. Helping banks meet the supply chain challenge. Accessed online: http://www.swift.com/products/trade_services_utility

Towill, D.R. (1997). The Seamless Supply Chain - The Predator's Strategic Advantage. International Journal of Technology Management 13(1) 37-56

Van der Veen, J.A., Venugopal, V. (2005). Using Revenue Sharing to Create Win-Win in the Video Rental Supply Chain. Journal of the Operational Research Society 56(7), 757762.

Vlachos, I.P. 2004. Critical Success Factors of Business To Business (B2B) E-Commerce Solutions to Supply Chain Management. In: Pardalos, P., Migdalas, A., Baourakis, G. eds. Supply Chain and Finance (pp. 161-175), London: World Scientific Publishing

Wuttke, D.A., Blome, C., Henke, M. (2013). Focusing the Financial Flow of Supply Chains: An Empirical Investigation of Financial Supply Chain Management. International Journal of Production Economics 145(2), 773-789. 


\section{Appendix}

Complementary to the introduced model calculations, two additional mathematical derivations are presented below.

Buyers: Considering both the revenue and cost function of single buyer functions (4) and (5), with the setting $R_{B}-C_{B}=0$ and solving for $A P_{B}$, the break even payment balance to a single buyer can be calculated with the following formula:

$$
A P_{B}^{*}=\frac{\left(\theta_{B} \cdot l_{B}\right)+\left(\kappa_{B} \cdot s^{\frac{1}{\sigma}}\right)+\left(v_{B} \cdot s^{\frac{1}{\mu}}\right)-\left(\alpha_{B} \cdot s^{\frac{1}{\tau}}\right)}{\left(\Delta W C_{B} \cdot s\right)+\left(\beta_{B} \cdot\left(i_{b}-i_{S}\right) \cdot\left(\left(D P O_{S C F}-D P O_{N S C F}\right) / 365\right) \cdot s^{\prime}\right)-\left(\beta_{B} \cdot i_{S} \cdot\left(\left(D P O_{S C F}-D P O_{N S C F}\right) / 365\right) \cdot s^{\nu}\right)}
$$

Financial institution: Considering both the revenue and cost function of the FI functions (7) and (8), with the setting $R_{F}-C_{F}=0$ and solving for $A P B_{F I}^{*}$, the break even payment balance to the FI can be calculated with the following formula:

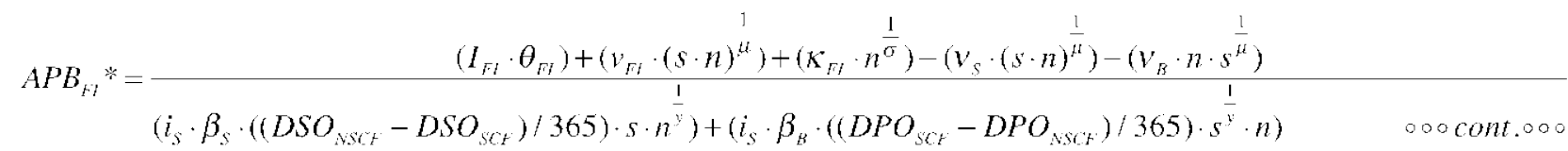

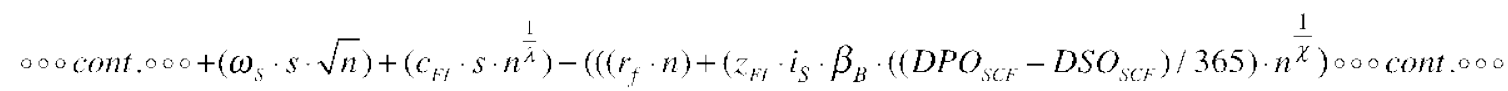

$$
\begin{aligned}
& \left.\left.\left.000 \text { cont.000+(l } l_{H i} \cdot \beta_{S} \cdot\left(\left(D S O_{N S C H}-D S O_{S C H}\right) / 365\right) \cdot \sqrt{n}\right)\right) \cdot s\right)
\end{aligned}
$$

